\title{
ESCENARIOS DOMINICANOS DE LA ESCUELA REPUBLICANA EN EL EXILIO, 1939-1945
}

Dominican scenes of the republican school in the exile, 1939-1945

\author{
Juan B. Alfonseca Giner de los Ríos ${ }^{\&}$ \\ Fecha de recepción: 20/05/2018 • Fecha de aceptación: 27/07/2018
}

Resumen. Este escrito describe la participación de los refugiados españoles en la enseñanza dominicana entre 1939 y 1945, lapso en el que arribaron y partieron los casi cuatro mil exilados que recibió la República Dominicana. Se trata de un estudio preliminar que procura, por una parte, ampliar el conocimiento sobre el impacto y la obra de los republicanos españoles en el país (trayendo a la luz referencias sobre los centros escolares que establecieron - que fueron 29 y no 6 como ha solido creerse-, así como apreciaciones sobre su participación dentro del sistema escolar dominicano), al tiempo que intenta, por otra, comprender los procesos de apropiación sociocultural de la escuela republicana en el exilio que tomaron lugar en la sociedad dominicana de entonces.

Palabras clave: Apropiación social de los proyectos escolares; Enseñantes refugiados; Refugiados enseñantes; dictadura trujillista.

Abstract. This paper describes the participation of Spanish refugees in Dominican education between 1939 and 1945, during which time almost 4,000 exiles arrived in the Dominican Republic. It is a preliminary study that seeks, on the one hand, to add to our knowledge of the impact and the work of the Spanish Republicans in the country, bringing to light references about the schools they established -which totalled 29 and not 6, as was believed - as well as an appreciation of their participation in the Dominican school system. We also attempt to understand the processes of sociocultural appropriation of the republican school in exile that took place in the Dominican society of the time.

Keywords: Social appropriation of school projects; Refugee teachers; Teachers refugees; Trujillo's dictatorship.

\footnotetext{
\& Instituto Superior de Ciencias de la Educación del Estado de México, Ex Rancho Los Uribe, Santa Cruz Atzcapotzaltongo, Toluca, Estado de México. j_alfonseca@yahoo.es.
}

Cómo citar este artículo: Alfonseca Giner de los Ríos, Juan B. «Escenarios dominicanos de la escuela republicana en el exilio, 1939-1945». Historia y Memoria de la Educación 9 (2019): 173-215. 


\section{INTRODUCCIÓN}

Frente a un campo temático cuya producción se ha dedicado centralmente al recuento de experiencias de desarrollo de instituciones escolares estables, duraderas y pedagógicamente perfiladas — como los emblemáticos colegios e institutos establecidos por los refugiados españoles de 1939 en México, Colombia, Chile y Venezuela-, ${ }^{1}$ la historia de los proyectos de aquellos que llegaron a Santo Domingo destaca por su carácter difuso, efímero y disperso, mostrándose factualmente al investigador más como una constelación de escenarios sueltos, difíciles de penetrar analíticamente, que como materia susceptible de reconstrucción documentada. Baste señalar que sólo uno, entre los casi treinta proyectos escolares que he referido en otra parte, ${ }^{2}$ alcanzó a legar documentación suficiente como para ser reconstruido. ${ }^{3}$

Es la resistencia empírica del objeto de conocimiento la que nos lleva a sólo comprometer en este escrito una descripción sumaria de los escenarios donde los refugiados desarrollaron procesos de enseñanza en la República Dominicana, nación que constituyó el segundo destino americano en importancia dentro de la diáspora global del exilio, y en donde el colectivo republicano vivió una experiencia marcadamente diferente de la vivida en las restantes sociedades americanas. Como lo señaló en sus Memorias Vicente Llorens Castillo, sin duda el primer his-

\footnotetext{
1 José Ignacio Cruz, La educación republicana en América, (1939-1982) (Valencia: Generalitat Valenciana, 1994); Claudio Lozano Seijas (ed.), 1939, el exilio pedagógico. Estudios sobre el exilio pedagógico republicano español de 1939 (Barcelona: Cooperativa Universitaria Sant Jordi, 1999); Salomó Marqués Sureda y José Martín Frechilla, La labor educativa de los exiliados españoles en Venezuela (Caracas: Universidad Central de Venezuela, 2002); María Eugenia Martínez Gorroño, «La educación en la Colombia liberal de los años 30 y 40: la trascendente contribución del exilio español consecuencia de la guerra civil de 1936-1939», Migraciones \& Exilios 4 (2003): 9-30; Juan José Reyes, «Escuelas, maestros y pedagogos», en El exilio español en México, 1939-1982 (México: Ediciones Salvat-Fondo de Cultura Económica, 1982), 177-205.

2 Juan B. Alfonseca Giner de los Ríos, El incidente del trasatlántico Cuba. Una historia del exilio republicano español en la sociedad dominicana, 1938-1944 (Santo Domingo: Archivo General de la Nación, 2012).

${ }^{3}$ Se trató del Instituto-Escuela fundado en la ciudad de Santo Domingo por la educadora valenciana Guillermina Medrano Aranda en 1941. Ver: Guillermina Medrano de Supervía, «Mi exilio en la República Dominicana: una obra educativa y varias mujeres ejemplares», en Cincuenta años de exilio español en Puerto Rico y el Caribe 1939-1989 (A Coruña: Edicios Do Castro, 1991), 345-355; Guillermina Medrano y José Ignacio Cruz, Experiencia de una maestra republicana (Valencia: Publicaciones de la Real Sociedad Económica de Amigos del País, 1998); Antares Ruíz del Árbol Cana, Hacer España en América, Guillermina Medrano Aranda (1912-2005): la pervivencia del Magisterio Republicano en el exilio americano (Santo Domingo: Academia Dominicana de la Historia, 2015).
} 
toriador de este segmento del exilio: «Casi podría decirse sin faltar gran cosa a la verdad que los emigrados españoles en América nos dividimos en dos grupos: el de los que vivieron en otras partes y el de los que estuvimos algún tiempo en Santo Domingo». ${ }^{4}$

¿Por qué polarizaba Llorens de modo tan rotundo la experiencia colectiva de los refugiados de la Guerra Civil en América? ¿Que hizo que la historia de los que estuvieron en Santo Domingo fuese tan especial y diferente?

He descrito esa experiencia en la obra antes citada. ${ }^{5}$ Poniendo en el menor número de palabras sus principales conclusiones, destacaría el hecho de que los refugiados españoles arribaron a la sociedad dominicana por gestión expresa del gobierno trujillista en el marco de una paradójica política exterior en la que un régimen totalitario, ávido de limpiar su imagen internacional, promovió la llegada masiva de un colectivo políticamente opuesto a sus formas de dominación. Esa política de imagen databa de inicios de la Guerra Civil y tuvo un repunte importante con la Conferencia de Evian (1938) sobre los refugiados centroeuropeos desplazados por el ascenso nazi. La llegada de los republicanos se vincula estrechamente con los correlatos de la Conferencia de Evian y fue un proceso en el que primó la desorganización, por mucho que la historiografía especializada afirme conexiones con el racismo anti-haitiano, el hispanismo y el interés demográfico.

Una vez en el país, los refugiados se volvieron un problema social de tal magnitud en cuanto a evidenciar la limitada capacidad dominicana para absorber refugiados y la desproporcionada oferta hecha en Evian de recibir hasta cien mil, que el régimen forzó su ida al campo, comenzando a poblarse las Colonias Agrícolas. ${ }^{6}$ A los pocos meses de

\footnotetext{
${ }^{4}$ Vicente Llorens, Memorias de una emigración (Barcelona: Ariel, 1975), 11.

${ }^{5}$ Alfonseca, El incidente del trasatlántico Cuba.

${ }^{6}$ Datando de 1907, el proyecto de colonización agrícola en tierras del Estado cobró fuerza durante la dictadura trujillista (1930-1961), que las insertó dentro de un plan de contención cultural del enemigo negro (principalmente Haití), en la región fronteriza y en zonas de inmigración de trabajadores agrícolas de color, como los ingenios azucareros del este del país. De hecho, las negociaciones establecidas para la inmigración de refugiados españoles contemplaron el arribo de algunos contingentes como colonos. Las Colonias a las que arribaron fueron: Juan de Herrera, Libertador y San Rafael de El Llano en la región fronteriza con Haiti; Constanza, La Cumbre y Medina en la región central, y Pedro Sánchez y Villa Trujillo en las llanuras azucareras del este. Ver: Alfonseca, El incidente del trasatlántico Cuba, 160-179.
} 
arribar, la situación del colectivo reclamaba la evacuación urgente pues no existían condiciones para que se adaptase a la realidad laboral dominicana. El régimen propició su salida parapetándose en un discurso ideológico basado en la «decepción inmigratoria». Empero, el ingreso de los EE.UU. a la Segunda Guerra Mundial tornó la navegación civil en el Mar Caribe algo escaso y muy peligroso, con lo cual los que permanecieron en el país, viviendo de modo precario, no lograron abandonarlo hasta casi el final de la guerra, en 1944.

En el ínterin, los refugiados lucharon desesperadamente por adaptarse a la vida dominicana, fuese con base en las ayudas humanitarias que recibirían, fuese con base en una inserción generalmente inestable y precaria en el mercado de trabajo. Como veremos decir líneas adelante al historiador Roberto Cassá, aunque los mantendría colectivamente asediados en los aciagos años 1940-1943, Trujillo explotaría su presencia como producto de vocación democrática, empleándolos en distintas tareas de elevación del servicio público. Como todos los dominicanos por aquellos días, los refugiados se vieron también obligados a los ritos del modelo de dominación (la loa obligada al Benefactor, que, en su caso particular, dio vida al discurso del agradecimiento por la hospitalidad humanitaria y la vocación de devolver y contribuir con la vida dominicana) trazando ciertas políticas de alianza estratégica en sus relaciones con el régimen.

La divisoria establecida por Llorens es palpable en las dinámicas que enmarcaron la gestación de proyectos de enseñanza por parte de los refugiados en la República Dominicana. Lo breve de su permanencia en el país, la dispersión del colectivo refugiado por el territorio, la precariedad que caracterizó sus intentos de sobrevivir y adaptarse a la vida dominicana, y la lógica de su inserción política en el orden de dominación dictatorial imperante fueron factores que definieron la naturaleza, el alcance y las condiciones de visibilidad de sus proyectos de enseñanza, según veremos al tratar los distintos escenarios en que los refugiados desarrollaron tales actividades.

La sociedad dominicana derivó hondos aportes del involucramiento de los refugiados en la esfera de la enseñanza y de la cultura en general. Sobre éstos existe en el presente cierta producción analítica que, empero, dista de haber profundizado sus muchos aspectos y que, incluso, 
parece haberse conformado con los hallazgos y las crónicas existentes. No dejan de citarse los emblemáticos aportes intelectuales realizados en el campo de la cultura, como la creación de la Escuela Nacional de Bellas Artes, el Teatro Escuela de Arte Nacional, el Conservatorio Nacional de Música y Declamación, la Escuela Diplomática y Consular, etc., lo mismo que su renovadora presencia en la vieja Universidad de Santo Domingo, rival de la de San Carlos de Lima en el reconocimiento de primicias en América. Sin embargo, poco se ha enfrentado el estudio de su involucramiento con las instituciones escolares básicas, con la divulgación de ideas en torno a la pedagogía y la escuela o con su desempeño dentro de las estructuras encargadas del diseño del sistema de enseñanza público dominicano.

Como veremos, en su esfuerzo por sobrevivir en las estrecheces del mercado social dominicano, los llegados animaron cerca de treinta proyectos escolares de carácter privado, al tiempo que ejercieron en instituciones dominicanas de enseñanza media y superior (tanto públicas como privadas) o se especializaron en la enseñanza particular a domicilio.

Este trabajo pretende abonar coordenadas útiles para la necesaria labor de profundización que habrán de desarrollar seguramente otros, deseablemente desde perspectivas que persigan no sólo situar las trayectorias americanas de la España peregrina, sino lo que significó la presencia de los refugiados en el mundo de la enseñanza dominicana.

\section{ENSEÑANTES REFUGIADOS Y REFUGIADOS ENSEÑANTES: LA DINÁMICA POLÍTICA, SOCIAL Y DEMOGRÁFICA DE LOS MAESTROS REPUBLICANOS EN LA SOCIEDAD DOMINICANA, 1939-1945}

Como figura retórica, el retruécano Enseñante Refugiado-Refugiado Enseñante encierra una realidad central que permitirá introducir aquí una breve visión de las grandes dinámicas sociopolíticas que enmarcaron la historia de los procesos educativos que gestaron o en los que se insertaron los exiliados.

Personas que enseñaban y se refugiaron /personas que se refugiaron y enseñaron. Dos formas de trayectoria constitutiva del cuerpo de enseñantes republicanos que laboró en el país, en gran medida determina- 
das por la penuria que generalmente arropó a este segmento del exilio, sin instituciones de auxilio relevantes, inmerso en un mercado social y laboral muy estrecho y sometido a la animosidad de un régimen que jugó sagazmente con su presencia en el país exhibiéndola como galardón de adhesión a principios humanitarios, aunque induciendo su salida paulatina del territorio nacional.

Según la nómina conformada por González Tejera con base en registros del Negociado de Inmigración, 129 personas expresaron a la autoridad dominicana tener por ocupación la enseñanza. ${ }^{7}$ Sometida a correcciones basadas en esa misma fuente, la nómina podría hacerse crecer a poco más de 140 enseñantes (ver listados anexos).

Las definiciones dadas a los agentes del Negociado de Inmigración dejan ver un abigarrado conjunto de especializaciones docentes. Sin embargo, sometiéndolas a una labor de crítica con el fin de arribar a conceptos más generales, emerge el siguiente escenario:

Cuadro 1. Maestros, profesores e inspectores refugiados en la República Dominicana, 1940

\begin{tabular}{|l|r|}
\hline Maestros de Primera Enseñanza & 84 \\
\hline Profesores de Instituto & 54 \\
\hline Inspectores & 2 \\
\hline Total & 140 \\
\hline
\end{tabular}

Fuente: Elaboración propia a partir de censos diversos.

El primer grupo integra los llamados Maestros Nacionales, ${ }^{8}$ definición que no siempre se consigna en los registros migratorios, que frecuentemente sólo señalan «maestro» o «maestro de escuela». Entre ellos figuran personalidades de interés en la escena pedagógica y

\footnotetext{
${ }^{7}$ Natalia González Tejera, «Nómina de republicanos españoles refugiados en República Dominicana (1940-1941)», Boletín del Archivo General de la Nación 38, no. 135 (2013): 33-154.

${ }^{8}$ Los Maestros Nacionales eran aquellos adscritos laboralmente al sistema escolar sostenido por el gobierno de España y suponían, desde antes de la segunda República, la posesión de un título de magisterio obtenido en una Escuela Normal. Quizá algunos hubiesen obtenido ese grado en el lapso republicano con el llamado Plan Profesional, lo que suponía una mayor formación.
} 
política española de la primera enseñanza hacia 1939, como Ramón Costa Jou y Josep Alcobé Biosca, figuras del movimiento freinetista en Lleida a inicios de los años treinta; Juan Campa Claverol y José Xena Torrents, maestros racionalistas; además de señalados cuadros radicales de la Federación Española de Trabajadores de la Enseñanza (FETE), ${ }^{9}$ entre los que se cuentan los hermanos José y Eduardo Bárzana Bárzana, Francisco Querol Amorós y Félix Artero Bernard. El segundo grupo integra un espectro de calificaciones más amplio, que va desde los profesores en Institutos de Segunda Enseñanza en general hasta los de Escuelas de Comercio y de Artes y Oficios. El tercero se formó con los Inspectores de Primera Enseñanza Luis Alaminos Peña y Fernando Sainz Ruiz.

Dos terceras partes de los enseñantes que integran la nómina eran hombres, cosa que llama la atención dado el grado de feminización del magisterio que primaba entonces en España, pero que puede explicarse en el hecho de que fuesen generalmente los jefes de familia quienes tramitasen el permiso de residencia por los costos que comportaba. ${ }^{10}$

Tres de cada diez de esos enseñantes lograron desarrollar labores remuneradas coherentes con su perfil profesional, fuese como instructores a domicilio, como maestros en escuelas de los propios refugiados o en escuelas dominicanas; algunos, incluso, pudieron insertarse en posi-

\footnotetext{
${ }^{9}$ Sindicato magisterial nacional nacido en junio de 1931 a partir de la reunión de distintas agrupaciones de maestros. En la definición de De Luis: «La Federación de Trabajadores de la Enseñanza (FETE), que agrupaba fundamentalmente a docentes de ideología socialista, contaba con un grupo significativo de maestros y profesores comunistas, algunos republicanos de izquierdas, y que había desempeñado un papel fundamental a lo largo del quinquenio republicano, se convirtió durante la guerra civil en el sindicato mayoritario y casi hegemónico — con la excepción de los anarquistas, que mantuvieron su propia y minoritaria organización sindical- de la enseñanza en España. Acabado el conflicto bélico - y durante su transcurso-, la represión franquista se centró en los militantes de la FETE». Francisco de Luis Martín, «El exilio de la Federación Española de Trabajadores de la Enseñanza en México (1939-1949)», Tzintzun. Revista de Estudios Históricos 63 (2016): 207.

${ }^{10}$ El trámite costaba 6 dólares, lo que equivalía, por ejemplo, a dos meses del subsidio que entregaba la Junta de Auxilio a los Refugiados Españoles (JARE en lo sucesivo) a los dependientes de la misma. El caso de algunos matrimonios de enseñantes - como el de Luis Leal y Pilar Munárriz o Ángel Pingarrón y Marta Benito-corroboran esta impresión, pues sólo los hombres figuran en el registro migratorio. La JARE fue fundada en Francia en julio de 1939 por la Diputación Permanente de las Cortes Republicanas en el exilio y dispuso de fondos del gobierno republicano para auxiliar y facilitar las condiciones de vida de los refugiados de la guerra civil. En Santo Domingo tuvo una delegación de representantes que canalizaban las ayudas que se recibían desde México.
} 
ciones de diseño dentro del servicio escolar público, o se especializaron como divulgadores de temas pedagógicos en la prensa periódica.

Por derivar de una fuente parcial, que comprende sólo poco más de la mitad de los llegados (51.9\%), la nómina que comentamos padece de un serio sub-registro. ${ }^{11}$ Conocer cuántos enseñantes comprendía la mitad restante supone recurrir a múltiples fuentes, menos específicas en lo relativo al perfil profesional pero lo suficientemente veraces como para permitir afirmaciones al respecto.

Valiéndonos de ellas, hemos logrado establecer una segunda nómina de 42 personas que también desempeñaron labores de enseñanza en las formas y los escenarios descritos. En ésta encontramos a educadores con trayectorias probadas en la península, como Guillermina Medrano Aranda, Dolors Canals Farriols, Manuel Cluet Santiveri, Malaquías Gil Arantegui o Aniceto León Garre. Sin embargo, la mayoría de los integrantes de esta segunda nómina cuenta con otras formaciones profesionales y su inserción en el campo de la enseñanza obedece, bien a la necesidad imperiosa de subsistir en el medio dominicano, o bien a la posesión de perfiles que les posibilitaron desempeñarla, como veremos más adelante.

En síntesis, bajo uno u otro trayecto de arribo a la enseñanza, no menos de 85 personas desempeñaron tal tipo de labores en la sociedad dominicana. ${ }^{12}$

¿Por qué se insertaron en el campo de la enseñanza? Evidentemente, en el esfuerzo por vivir y adaptarse a la sociedad a la que arribaban, que tenía grandes limitaciones en términos de mercado laboral, la gran mayoría desplegó tales actividades en el marco de una angustiosa situación económica, salvo un pequeño núcleo que pudo acceder a empleos estables en alguno de los proyectos de política cultural que entonces animaba el régimen trujillista, que siempre tuvo claro que el perfil intelectual de los llegados le permitiría hacerlos despegar.

Fue particularmente el caso de quienes se hallaban en las tristemente célebres Colonias Agrícolas del Estado — proyecto insuficiente-

\footnotetext{
${ }^{11}$ Los Permisos de Residencia conservados en el Archivo General de la Nación totalizan 2.046 cédulas. Con base en otras fuentes, hemos arribado a un censo general preliminar que comprende 3.935 personas.

12 Excluimos deliberadamente de este cálculo — por ser tema ya suficientemente conocido- a los 24 profesores que laboraron en la Universidad de Santo Domingo.
} 
mente planificado, plagado de irregularidades en el manejo de los recursos entregados por los organismos de ayuda al exilio español- a las que fueron a dar grandes contingentes directamente al desembarcar en suelo dominicano, y en las que hubieron de subsistir precariamente hasta que lograron salir del país. Lanzados a roturar terrenos eriazos e insalubres, desprovistos de conocimientos, herramientas, animales y vivienda suficientes, el común de los colonos migraría a los pueblos circundantes en busca de empleo, derrotero en el que muchos ensayaron la enseñanza como medio de subsistencia. Esta dinámica esparció por la geografía dominicana los proyectos de enseñanza de los llegados, hecho que resulta peculiar frente a otras experiencias americanas del exilio. Sin embargo, no era privativa de los radicados en el campo, pues en las ciudades muchos optaron por subsistir como enseñantes por la imposibilidad de hallar empleo en sus campos profesionales.

\section{Los enseñantes}

El grueso de las personas de que hablamos laboró en proyectos escolares del propio exilio o en planteles dominicanos. Aunque existió el empleo como enseñantes a domicilio, su extensión es difícil de precisar pues su conocimiento depende de fuentes testimoniales y éstas las han producido sólo un corto número de personas.

Comenzando por la conocida relación de tutoría de José Almoina Mateos con Ramfis, el hijo del dictador, el fenómeno de la enseñanza a domicilio fue relativamente frecuente. Ramón Costa Jou, el maestro freinetista que luego pasaría a Cuba y más tarde a México, relata haber sido enseñante privado de los hijos de un industrial de la vieja colonia española, pues éste no "quería que sus hijos [...] tuvieran contacto con los dominicanos, por cuestiones de raza». ${ }^{13}$ Clases particulares de profundización de conocimientos para la presentación de exámenes oficiales proporcionaron la materia a la que varios se dedicaron. Incluso algunas mujeres contratadas como cocineras en domicilios de la vieja colonia española, extendieron sus labores a la educación de menores. ${ }^{14}$

\footnotetext{
${ }^{13}$ Entrevista a Ramón Costa Jou. PHO/10/84 Archivo de la Palabra del Instituto Nacional de Antropología e Historia (APINAH).

${ }^{14}$ Podrían citarse los casos de Manuel Barberá Roda, Cristina Ulibarri González, Poncio Sabater Casellas y Amelia Quintana Barrón, también tutores en domicilios de la élite burocrática y empre-
} 


\section{Las escuelas del exilio español en la sociedad dominicana}

Escuelas creadas por refugiados hubo muchas más de las seis que suelen referirse. ${ }^{15}$ En realidad, las establecidas fueron, al menos, 29, como puede apreciarse en el cuadro 2 .

Antes de describir los escenarios en que se gestaron esas escuelas, debe destacarse el gran número de localidades donde existieron, rasgo que contrasta con otras experiencias americanas donde los planteles del exilio se concentraron en unas pocas ciudades. ${ }^{16} \mathrm{~A}$ pesar de que casi todas las localidades eran cabecera de provincia (exceptuadas cuatro), se trataba de sencillos poblados de pocos miles de habitantes que distaban de cascos urbanos como el viejo Santo Domingo de Guzmán la ciudad capital-, Santiago, Puerto Plata o San Pedro de Macorís, donde existía un ambiente propicio a las iniciativas escolares de los llegados.

Las fuentes para reconstruir la historia de esos proyectos son muy escasas. En el común de los casos sólo se cuenta con escuetas notas de prensa que dan aviso de su apertura o que les dedican algún comentario, ignorándose aspectos de interés como la matrícula con que contaron, la pedagogía que practicaron, etc. Casi todos tuvieron una vida corta, fuese porque sus gestores se marchaban del lugar o del país, porque cambiaban de actividad por no poder subsistir con los recursos que proporcionaba la enseñanza, o porque pasaban a integrarse en planteles oficiales. Pocos alcanzaron, por ello, un tercer año actividad, cosa que sólo lograron el Instituto-Escuela de Santo Domingo; la Academia Antillana de San Pedro de Macorís, el Instituto-Escuela Cervantes de La Romana y el Instituto Iberia de Navarrete.

sarial. María Molina, «Republicanos españoles en el Caribe y en México. Tres naciones, tres momentos, un mismo exilio», en 1939, el exilio pedagógico, ed. Claudio Lozano (Barcelona: Cooperativa Universitaria Sant Jordi, 1999), 119-133. [Entrevista a Mercedes Sabater], Santo Domingo, 12 de septiembre de 1988, colección personal del autor.

${ }^{15}$ Llorens, Memorias de una emigración, 58-60; José del Castillo y Manuel García Arévalo, «La emigración republicana española: aportes a la República Dominicana», en El exilio republicano español en la sociedad dominicana, coord. Reina Rosario Fernández (Santo Domingo: Archivo General de la Nación, 2010), 235-268; Salomó Màrques Sureda, «Sobre l'exili del magisteri republicà (193639). Reflexions i suggeriments», Educació i Història: Revista d'Història de l'Educació 12 (2008): 57.

${ }^{16}$ Ver, por ejemplo: Cruz, La educación republicana, 53-100. 
Cuadro 2. Escuelas establecidas por los refugiados españoles en la República Dominicana

\begin{tabular}{|c|c|c|c|}
\hline Lugar & Nombre del plantel & Director & Planta $^{\mathrm{a}}$ \\
\hline \multirow{8}{*}{ Santo Domingo } & $\begin{array}{l}\text { Colegio Sagrado Corazón de } \\
\text { Jesús. }\end{array}$ & Enrique Darnell Martí & 5 \\
\hline & Instituto Cristóbal Colón & Juan Pablo García & 23 \\
\hline & $\begin{array}{l}\text { Instituto Escuela Juan Pablo } \\
\text { Duarte }\end{array}$ & José María Casasas & 12 \\
\hline & Instituto Escuela & Guillermina Medrano & 6 \\
\hline & Escuela Española & Jesús Abadías Lamuela & 3 \\
\hline & Centro Español Democrático & - & - \\
\hline & $\begin{array}{l}\text { Escuela Superior de Ciencias } \\
\text { Económicas }\end{array}$ & Jesús Sorribés Soler & 7 \\
\hline & Sociedad de Arte Dramático & Maruja Fernández de F. & 1 \\
\hline \multirow{2}{*}{ Santiago } & $\begin{array}{l}\text { Nuevo Instituto Escuela } \\
\text { Cervantes }\end{array}$ & José Rivero Orellana & \\
\hline & Escuela de Arte Dramático & Carola Yonmar & 2 \\
\hline Navarrete & Instituto Iberia & José Giménez Miralles & 1 \\
\hline \multirow{2}{*}{ Puerto Plata } & Instituto Luís Vives & Francisco Querol Amorós & - \\
\hline & Academia Renovación & David Arias Rodríguez & 6 \\
\hline Moca & $\begin{array}{l}\text { Instituto Escuela } \\
\text { Hispanoamericano }\end{array}$ & Francisco Ruíz Avilés & 2 \\
\hline Salcedo & Colegio España & Gregorio Salanova Orueta & - \\
\hline La Vega & Nueva Institución de Cultura & José Barzana Barzana & 4 \\
\hline San $F^{\mathrm{co}}$ de Macorís & Escuela de Declamación & Emilio Aparicio Martínez & 1 \\
\hline \multirow{4}{*}{$\begin{array}{l}\text { San Pedro } \\
\text { de Macorís }\end{array}$} & Instituto de Estudios Técnicos & Joaquín Hurtado Marhuenda & 7 \\
\hline & n.d. & Luis Espinal & 2 \\
\hline & Academia Benefactor Trujillo & Miguel Arnedo Díaz & 3 \\
\hline & Academia Comercial Antillana & Ángel Pingarrón Hernández & 3 \\
\hline La Romana & Instituto Escuela Cervantes & Tiburcio Millán López & 4 \\
\hline El Seibo & Instituto Hostos & José Alcobé Biosca & 5 \\
\hline Pedro Sánchez & Club Hispanodominicano & José Farreras Borull & - \\
\hline Montecristy & Compañía Escolar de Variedades & Manuel Calvo Cano & - \\
\hline Dajabón & Instituto Generalísimo Trujillo & Dolores de los Ríos Poveda & 7 \\
\hline Las Matas de Farfán & n.d. & Mariano Viñuales Fariñas & 3 \\
\hline \multirow{2}{*}{$\begin{array}{c}\text { San Juan de la } \\
\text { Maguana }\end{array}$} & Escuela de Pintura & Pedro Bargalló Cervelló & - \\
\hline & Academia Comercial Rossetta & José Abella Peset & 2 \\
\hline
\end{tabular}

${ }^{a}$ Número de enseñantes españoles, excluido el director.

Fuente: «Registro de las escuelas particulares y semioficiales», Revista de Educación 57 (1940); Diario La Nación. 
Ninguno de los proyectos contó con apoyo de los organismos de ayuda al exilio español, como sucedió en México con, por ejemplo, el Colegio Madrid o el Instituto Luis Vives, partiendo la mayoría con recursos de los propios refugiados o de mecenas dominicanos. Sólo dos proyectos tuvieron por sentido instruir a los hijos de los propios refugiados, especializándose casi todos en atender demandas no satisfechas por el sistema escolar nacional. La gran mayoría de las escuelas ofreció varios tipos y niveles de enseñanza, rasgo que también parece ser distintivo de la experiencia dominicana.

Prácticamente todos los proyectos se crearon en el curso de 1940, año en el que arribó al país la mayoría de los refugiados. La eclosión simultánea de los centros en ese lapso habla tanto de las precarias condiciones de vida que enfrentaron, de entrada, los refugiados, como del clima de tensión que recayó sobre ellos tras el rechazo dramático del contingente de 600 personas que arribó a bordo del Cuba el 6 de julio de 1940, cuyo desembarco no fue autorizado por el gobierno dominicano que, oficiosamente, se decía:

sorprendido al encontrarse con que entre los miles de españoles enviados por los comités citados, no se encontraba ningún agricultor propiamente dicho, y que en cambio, de manera sistemática, era enviada a nuestro país una cantidad de inmigrantes francamente indeseables - con muy pocas excepciones- ya que no se trataba meramente de personas cuyas ideas o filiación política les obligaron a salir de España [...] sino de gente de profesión desconocida aún en su propio país, y cuya historia prácticamente comienza con la guerra [...] con títulos y cargos equívocos, que sólo justifican —en algunos casos- papeles de dudosa garantía. ${ }^{17}$

Un duro ataque a la identidad y la disposición del colectivo republicano, al que seguirían varios más en la prensa oficialista, que fueron moldeando la discursiva con que comenzaría a representarse públicamente la presencia de los refugiados españoles: la decepción inmigratoria y la peligrosidad política. Cassá ha definido de modo muy preciso el

\footnotetext{
17 «Los refugiados del trasatlántico francés «Cuba», en situación muy difícil para poder desembarcar en el país», La Nación (Ciudad Trujillo), 9 de julio de 1940.
} 
marco político que envolvió la acción de los llegados en su esfuerzo por adaptarse a la vida dominicana:

Trujillo se movió con una táctica muy refinada en relación a los españoles. Explotaba su presencia como demostración de vocación democrática y pro-occidental, al tiempo que, desde muy pronto, estrenó el procedimiento de denunciarlos como portadores de ideas extrañas y peligrosas, con el fin de ponerlos a la defensiva y evitar que incidieran en forma negativa sobre la reproducción del poder tiránico [...] Y aunque los sometió a ataques despiadados, no se propuso propiciar su salida masiva, pues el contexto de la Guerra hacía conveniente la prolongación de su presencia [...] En todo momento se planteó utilizar a los refugiados españoles en tareas técnicas, administrativas y culturales, como medio de reciclar la manipulación política de su presencia. Esto fue tanto más favorable para el tirano en la medida en que algunos hicieron pronunciamientos de alabanza al Gobierno dominicano. ${ }^{18}$

Como reacción, los refugiados dieron forma pública a una identidad basada en el obligado agradecimiento al Dictador y la disposición manifiesta al trabajo productivo. La frase «El pensamiento para España; el esfuerzo para Santo Domingo» concreta bien los términos de la identidad que envolvería la faz pública de sus actividades en la sociedad dominicana. ${ }^{19}$

Esas tensiones enmarcaron el nacimiento de proyectos concretos, como el de la escuela de la colonia agrícola de «Pedro Sánchez» que comentaremos después, pero fue también perceptible en los discursos y rituales de presentación pública de los planteles e, incluso, en sus apelativos mismos. Sobre esto debe señalarse que, aunque "Instituto-Escuela» resulte una definición común en muchos de los planteles (evocadora, claro está, del ideario pedagógico republicano), existe también una serie de apelativos evocadores de la España imperial que abrazaba imagina-

\footnotetext{
18 Roberto Cassá, «Incidencia política de los republicanos españoles en la República Dominicana», en El exilio español en la sociedad dominicana, 115-116.

19 «iGanar la Emigración! Soldados del Trabajo: el pensamiento para España y el esfuerzo para Santo Domingo», Hogar 2, no. 15 (1940): 4-5.
} 
riamente la dictadura en su empeño por reforzar la idea de una comunidad hispano-dominicana como vía para la contención del enemigo negro que acechaba al occidente de la isla (Haiti). Denominaciones como "Cristóbal Colón», "Hispano-dominicano», «Hispanoamericana», «Dominico Español» pueden interpretarse en ese marco de acción política, que es claro en las que directamente aluden al dictador ( Benefactor Trujillo», «Generalísimo Trujillo»).

Ese marco general de interacción política pautó formas de apropiación sociocultural precisas en la vida de las escuelas, como destacaremos al describir ahora los escenarios de la escuela republicana en su exilio dominicano.

El más ambicioso de los proyectos educativos fue el que dio vida al Instituto de Segunda Enseñanza y Politécnico Cristóbal Colón, en agosto de 1939. Ubicado en la ciudad de Santo Domingo, en una finca de la Avenida Independencia n. ${ }^{\circ}$ 92, el Instituto contó con una plantilla de 23 profesores refugiados y ofreció varios niveles de enseñanza (primaria superior, bachillerato y normal), además de cursos de idiomas, dibujo, pintura y carreras técnicas. Esto lo convirtió en uno de los colegios más completos del país, si no el que más, pues también contaba con régimen de internado. Su director fue Juan Pablo García Álvarez, abogado, y entre sus profesores se contaron muchos que luego destacarían en la escena intelectual y cultural dominicana, como Javier Malagón Barceló, Jesús de Galíndez, Alfredo Matilla, Ramón Suárez Picallo, Carlos Solaeche o José Vela Zanetti. ${ }^{20}$

El Cristóbal Colón fue creado por la Sociedad Fomento de las Artes y las Ciencias, asociación cultural establecida en Santo Domingo en julio de 1939, presidida por el propio García Álvarez en unión de otras personalidades del exilio, quienes, en colaboración con funcionarios del régimen como el rector Julio Ortega Frier y los secretarios de Estado Virgilio Díaz Ordoñez y Arturo Logroño, concibieron un proyecto de élite. La Sociedad tenía como propósito

el desenvolvimiento cultural de los habitantes de la República Dominicana, sin distinción de rasgos sociales o religiosos, para lo cual fundará un colegio [...] una Biblioteca [...] patrocinará

\footnotetext{
20 «Registro de las escuelas particulares y semioficiales», Revista de Educación 57 (1940): 64-74.
} 
[...] conferencias de intelectuales dominicanos y extranjeros sobre $[\ldots]$ las ciencias y las artes. ${ }^{21}$

Un vistazo al folleto de presentación del Instituto deja clara su apuesta social y cultural..$^{22}$ Lejos de presentar consideraciones pedagógicas, el folleto privilegia aspectos relacionados con la autoridad, la normalidad y la distinción. En la sección «Dirección y Disciplina» se destaca, por ejemplo, la autoridad absoluta del Director respecto de cualquier tema escolar y la división del alumnado en secciones masculina y femenina, cada cual con una dirección de su sexo. En cuanto a «Matrícula», indica que los aspirantes se someterían a un riguroso escrutinio, debiendo presentar primero, una «Instancia de Matrícula» a la que seguiría un examen médico cuyo objeto sería detectar enfermedades contagiosas o «defectos físicos» que pudiesen «ocasionar molestias a sus compañeros».

Como visión, el instituto privilegiaría la «corrección», nombrando un profesor abocado a observar «las buenas maneras en todos los actos de la vida escolar», impartir conferencias periódicas sobre la materia y observar metódicamente el avance relativo de los alumnos. La descripción del «Equipo Escolar» establece claramente la distinción social pues prescribía que los internos estarían provistos de cuatro tipos de uniforme («de Estudio», "Media Gala», "Gala» y «Deporte»). Respecto de la «Formación Moral», se establecía que «las enseñanzas del Instituto dejarán lugar a las creencias religiosas, para las que se garantiza absoluto respeto». En el segmento de «Recompensas y Sanciones», se indica que «todo acto meritorio pueda dar lugar a las primeras, así como toda falta a las segundas». La principal de las recompensas lo sería el «Premio Benefactor», consistente en un viaje a Europa de no menos de quince días, que se entregaría al mejor alumno del año. El premio contó con la aportación de 1.000 dólares americanos donados por Rafael L. Trujillo, el «Benefactor de la Patria», como solía referírselo entonces. $^{23}$

\footnotetext{
21 «Estatutos de la Sociedad Fomento de las Artes y las Ciencias», julio de 1939, Papeles de Julio Ortega Frier, Biblioteca Nacional de la República Dominicana (BNRD en lo sucesivo).

22 Instituto Cristóbal Colón (Ciudad Trujillo: Impresora La Opinión, 1939).

23 «Asamblea de la Sociedad Fomento de las Artes y las Ciencias. Resolución», julio de 1939, Papeles de Julio Ortega Frier, BNRD.
} 
A pesar del apoyo de ese mecenas supremo y del prestigio que le granjearon las aplaudidas conferencias que impartieron al público general sus profesores, el Cristóbal Colón duró poco tiempo, dejando de existir en abril de 1940 en el marco de una sombría trama todavía por explicar.

Salvo este ensayo inicial, ampliamente difundido por la prensa nacional durante el verano de 1939 como símbolo de excelencia y modernidad académicas, ${ }^{24}$ las demás escuelas comenzaron a crearse con la llegada del grueso de los refugiados entre fines de ese año y la primavera de 1940.

Santo Domingo — rebautizada Ciudad Trujillo entonces- fue el espacio donde afloró el segundo proyecto, denominado Instituto Escuela Juan Pablo Duarte, dirigido por el también abogado José María Casasas, que ofreció estudios de primaria superior, enseñanza normal y cursos preuniversitarios. Entre los 12 enseñantes que laboraron en él encontramos a Manuel Cluet Santiveri, Estrella Cortichs Viñals, Ramón Medina Tur y Felipe Andrés Cabezas, quienes más tarde proseguirían su trayectoria en otras naciones americanas. En su primera etapa, el instituto laboró por la noche y se alojó en los bajos de la Escuela Normal de Señoritas. La prensa lo presentó como opción «para aquellos adultos que por tener durante las horas del día una ocupación se ven privados de asistir a Escuelas o centros de enseñanza de carácter superior ${ }^{25} \mathrm{~A}$ él fueron canalizados los alumnos del Cristóbal Colón cuando éste fue cerrado.

Casi en los mismos días en que abría el Juan Pablo Duarte, el abogado Enrique Darnell Martí tomaba la dirección del Colegio Sagrado Corazón de Jesús, plantel que existía desde hacía años. Con él se emplearon cinco enseñantes españoles más. En una carta, Darnell aclaraba que el colegio «no obstante las equívocas suposiciones a que pudiera inducir el circunstancial mantenimiento de su nombre [...] reflejará el espíritu de la Institución Libre de Enseñanza y el Instituto-Escuela». ${ }^{26}$

\footnotetext{
${ }^{24}$ «Reportajes de La Opinión: Impresiones de una visita al Instituto Cristóbal Colón», La Opinión (Ciudad Trujillo), 28 de agosto de 1944.

25 «Mañana se inaugura el Instituto Escuela Juan Pablo Duarte», La Nación (Ciudad Trujillo), 26 de febrero de 1940.

${ }^{26}$ Enrique Darnell Martí, "Carta», febrero de 1940, Archivo Personal de Bernardo Giner de los Ríos (APBGR en lo sucesivo).
} 
Tal tipo de refundaciones (no meros cambios de dirección, en tanto pretendieron nuevos planteamientos pedagógicos) ocurrió en ocasiones. Fue el caso, por ejemplo, de la Academia Antillana y de la Academia Renovación, establecidas en los puertos de San Pedro de Macorís y Puerto Plata. La primera databa de los años veinte y de ella se hizo cargo en 1941 Ángel Pingarrón Hernández, psicólogo, ex becario de la Junta de Ampliación de Estudios, quien tenía establecida con su mujer una modesta Academia Minerva que fusionó con el plantel que dirigiría durante tres o cuatro años. La segunda fue establecida en septiembre de 1940 por Luis Pérez del Real (diplomado en las escuelas Normal de Sevilla y Superior del Magisterio de Madrid) a instancias de la sociedad cultural Renovación, activa desde 1928.

Los discursos que merodean la descripción de ambos planteles expresan muy bien la sintomática del agradecimiento que instaló en la representación de dominicanos y españoles el incidente del trasatlántico Cuba. Sobre la Academia Antillana decía en 1943 el diario La Opinión:

A la llegada a la Hispaniola, con la retina plena de visiones de horror, los refugiados españoles, que sólo habían recibido en Francia el desprecio como acogida, recibieron en contraposición, además del pan material, ese pan espiritual de la simpatía y el afecto de sus hermanos dominicanos, y ellos, agradecidos [...] prometieron unir su esfuerzo maravilloso al que, desde todos los campos bajo la bien llamada Era de Trujillo, está haciendo la República, hábilmente dirigida por su Benefactor: el Generalísimo Trujillo Molina, Primer Maestro de la República. ${ }^{27}$

En tanto, los profesores de la Academia Renovación inscribían la siguiente leyenda en su folleto de presentación:

Esta Academia se ha creado con la protección de las dignas autoridades y de algunas de las más distinguidas familias de Puerto Plata para aprovechar la aportación al acervo cultural vernáculo, de la labor de un grupo de profesores españoles, que

\footnotetext{
27 «Una escuela que honra la instrucción. La Academia Antillana», La Opinión (Ciudad Trujillo), 18 de agosto de 1943.
} 
en esta forma pretenden pagar el bien que les hace la República, al abrirles sus brazos acogedores. ${ }^{28}$

Esas identidades discursivas se hicieron presentes en el establecimiento de proyectos que directamente colocaron el apelativo del dictador en la denominación del centro, como la Academia Benefactor Trujillo establecida a inicios de 1940 en San Pedro de Macorís por Miguel Arnedo Díaz, Maestro Nacional y ex Inspector interino de Enseñanza, ${ }^{29}$ y el llamado Instituto Dominico-Español Generalísimo Trujillo fundado en el poblado de Dajabón por Dolores de los Ríos Poveda, enfermera y puericultora. $^{30}$

El caso del Instituto Dominico-Español Generalísimo Trujillo permite ilustrar una vía central de gestación de los proyectos escolares: la debida a la diáspora desde las Colonias agrícolas.

Contigua a la ciudad de Dajabón, la Colonia Agrícola Libertador fue de las primeras en recibir contingentes directa e improvisadamente instalados tras desembarcar en suelo dominicano, y fue también la que primero y más rápidamente se desintegró. Un mensaje enviado a las Sociedades Hispanas Confederadas por el señor José Byaina, permite captar la situación vivida en ellas:

He llegado a esta República el 24 de febrero último en el $L a$ Salle y mi asombro fue grandioso cuando fuimos trasladados de Puerto Plata a Dajabón sin que se nos diera un solo centavo para poder beber un poco de agua pues en esta colonia, incluso se paga el agua. Instalados ya en Dajabón se nos dio albergue en unas chozas que habían sido construidas por haitianos y que ahora estaban vacías por haber sido éstos expulsados del país. Ni qué decir tiene que la mayoría [...] está faltada de las más elementales reglas de higiene, ni agua, ni luz, ni utensilios para limpiarlas, teniendo que estar expuestos a todas las enfermedades [...] Comimos un mes en comedor popular tan mal instalado

\footnotetext{
${ }^{28}$ Luis Pérez del Real, Academia Renovación, julio de 1940. Documento facilitado por la historiadora Rocío Arnal Lorenzo.

29 «Dirigida por un Profesor español funcionará una academia en Macorís», La Nación (Ciudad Trujillo), 25 de enero de 1940.

30 «Un Instituto Dominico Español en Dajabón», La Nación (Ciudad Trujillo), 13 de marzo de 1940.
} 
[...] que sufrimos dos fuertes intoxicaciones [...] pues comíamos la carne descompuesta [...] Todo lo expuesto motivó una serie de quejas de los españoles residentes en ésta [...] pidiendo que se les diera en metálico lo que se les daba en comida al efecto de que cada familia pudiera condimentárselo a su gusto y poder comer lo más limpio posible [...] dieron $\$ 5.00$ mensuales por persona, cobraderos el día 15 y 30 de cada mes [...] tenían que dar los cacharros [...] para cocinar, cosa que prometieron pero que se olvidaron de dar. El día 18 [...] pagaron $\$ 2.50[\ldots]$ como es natural, correspondía [...] el día 3 de abril la otra mitad. No fue así. Se pagó el día 13 con diez días de retraso, viéndose las familias muertas de hambre, vendiendo sus ropas para poder comer. ${ }^{31}$

Compañera de Byaina durante la travesía a bordo del La Salle, la profesora Dolores De los Ríos decidió - antes que él- emigrar de la colonia para dirigirse a Dajabón donde, en unión de sus compañeros correligionarios Juan Sendra Siscart, Avelina Pijoan, Emilio García Rovira, Francisca Riera, José Farreras Borull, Manuel Pedreira y Cristina Rolland, - todos afiliados a las Juventudes Socialistas Unificadas de Cataluña-, decidieron establecer el plantel bajo el apelativo estratégico del Generalísimo. Los siete era enseñantes afiliados a la FETE. ${ }^{32}$

Otros futuros enseñantes de los dominicanos migraron desde esa y las demás Colonias, impactando de modo novedoso la vida de pueblos sumidos en ciertos tipos de olvido educacional, como El Seibo, Navarrete, La Romana, Las Matas de Farfán, San Juan de la Maguana o Montecristy, que fue a donde llegaron desertores de las Colonias que pasaremos a referir.

También el coronel Ángel Rayo del Campo había llegado a la colonia «Libertador», como Byaina y De los Ríos, emigrando con su gran amigo, el teniente Manuel Calvo Cano, a la no muy lejana ciudad de Montecristy donde, tras una serie de afortunados encuentros, encontraron trabajo. Ambos eran ingenieros militares. Del Rayo se empleó como

\footnotetext{
31 José Biayna, "Carta», abril de 1940, Papeles de Julio Ortega Frier, BNRD.

32 Entrevista al señor José Farreras Borull, Ciudad de México, 18 y 21 de agosto de 1989, colección personal del autor.
} 
agrimensor en la Grenada Fruit Company; Calvo lo consiguió como maestro de matemáticas en la Escuela Normal, donde, adicionalmente, instaló una Compañía Escolar de Variedades llamada La Farándula, que preparaba como enseñante en su domicilio. ${ }^{33}$

No muy lejos de allí, en la colonia de El Llano, el líder anarquista Mariano Viñuales Fariñas padecía el rigor del trabajo agrícola que se realiza sin experiencia, buscando en qué emplearse para poder subsistir. Junto con sus camaradas Fidel Miró Solanes, Luis Romero Solano y José Giménez Miralles decidieron montar una escuela en el cercano poblado de Las Matas de Farfán, que visitaban cada cierto tiempo con el fin de impartir clases de regularización de nivel superior. Las clases se daban en un aula de la escuela pública del lugar y en el domicilio de sus alumnos. ${ }^{34}$ Miró, Romero y Viñuales abandonarían la colonia poco tiempo después, pero Giménez Miralles continuó en la trayectoria de la vocación que pareció encontrar en suelo dominicano, llegando más tarde al distante pueblo de Navarrete, donde estableció el Instituto Iberia, plantel en el que enseñaban él y su esposa Luisa Recio. El instituto tuvo tal éxito que fue luego trasladado a Santiago de los Caballeros, la segunda ciudad del país, donde todavía hoy enseñan sus descendientes. $^{35}$

Por su parte, desde la Colonia Juan de Herrera (adonde llegaron también anarquistas de la talla de José Carbó Carbó, José Peirats o Severino Campos), los re-emigrantes tendieron a dirigirse a San Juan de la Maguana, la pequeña capital provincial donde personas como José Abella Peset (de profesión desconocida) y Pedro Bargallo Cervelló (pin-

\footnotetext{
${ }^{33}$ Entrevista al ingeniero Ángel Rayo del Campo, Ciudad de México, 20 de julio de 1989, colección personal del autor.

${ }^{34}$ Entrevista al señor Fidel Miró, Ciudad de México, 8 de julio de 1989, colección personal del autor.

${ }^{35}$ Un testimonio acerca de Giménez Mirallés, deja ver que las actividades de los colonos en Las Matas de Farfán tuvieron la intención — por rudimentaria que fuese- de dar vida a un plantel. Refiriendo el periplo dominicano del matrimonio señala: «Allí los mandaron a la jungla, primero pusieron una plantación de cacahuetes, que les fue como el demonio, y después Pepe Miralles, que era artillero de carrera, dijo que lo único que sabía hacer era enseñar, así que puso una escuela e hizo un barracón, donde alfabetizó a todos los críos de la zona, a todos los inditos de por allá. Los hacía desfilar y mantenían una disciplina militar. Luego se fueron a vivir a otra población y luego a Santiago de los Caballeros». Mercedes Orgaz, Testimonio desde la retaguardia. Las memorias de una funcionaria del Gobierno de la República durante la Guerra Civil y el exilio (Barcelona: Fundació Privada Ciencia en Societat, 2007), 25.
} 
tor y astrónomo) instalaron también escuelas. El primero abrió la Academia Comercial Rosseta, todavía activa hacia finales de 1943, en la que se dictaban cursos de mecanografía, taquigrafía y teneduría de libros, además de francés, especialidades que frecuentemente se encontraron en las escuelas de los refugiados. ${ }^{36} \mathrm{El}$ segundo instaló una Escuela de Pintura antes de partir rumbo a Venezuela, donde proseguiría una trayectoria vinculada a la enseñanza como fundador del Planetario Humboldt.

Sin embargo, fue de Pedro Sánchez, la colonia situada en la llanura azucarera del este del país, desde donde saldrían los proyectos escolares que mayor eco tuvieron en la percepción de los dominicanos, pues desplegaron una labor cultural que fue mostrada por la prensa como el fruto virtuoso de la atinada política inmigratoria de Trujillo. Pedro Sánchez fue la colonia «estrella». La creación en ella del Club Hispano Dominicano fue el corolario emblemático de la disposición de los llegados a entregarse a la labor productiva y a la difusión de benignos influjos culturales, que fueron divulgados con las consabidas aristas racistas e hispanistas que animaba el régimen. El Club sostuvo una escuela (más bien tres, pues en el mismo local había clases para niños españoles y dominicanos, clases nocturnas de alfabetización para adultos y clases de Corte y Confección). ${ }^{37}$

A El Seibo, la cabecera provincial cercana, llegó desde la colonia un grupo de profesores que instalaron el Instituto Hostos, que vino a ser el primer plantel de estudios secundarios y normalistas en la historia local. ${ }^{38}$ En él impartieron maestros nacionales como José Alcobé Biosca (su director), Félix Artero Bernard, Jesús Abadías Lamuela, Ricardo Pons Rubio, el abogado Claudio Fournier Canela y Luis García Lago. ${ }^{39}$

\footnotetext{
36 "Academia Comercial Rosseta», Democracia (Ciudad Trujillo), 7 de agosto de 1943.

${ }^{37}$ Españoles en Pedro Sánchez. Publicación del Club Hispano-Dominicano (Ciudad Trujillo: Talleres Pol Hermanos, 1941).

${ }_{38}$ «Inaugurado el Instituto Hostos de enseñanza secundaria dirigido por un grupo de profesores españoles», La Nación (Ciudad Trujillo), 4 de septiembre de 1940.

${ }^{39}$ Se trata de Luís Pérez García-Lago, secretario general del Partido Socialista Unificado de Cataluña en Lleida durante los treinta, que se encontraba en la isla con Aurelia y Avelina Pijoan, líderes de esa formación política; la primera, su esposa. Ver: Antonieta Jarne, «Geografías familiares bajo la dictadura franquista: exilio, clandestinidad, prisión», Hispania Nova. Revista de Historia Contemporánea 8 (2008) http://hispanianova.rediris.es. (consultado el 24-10-2017).
} 
El Instituto Hostos tuvo un profundo impacto en la vida de la ciudad de El Seibo, no sólo porque llenó expectativas insatisfechas de formación del alumnado local, sino por el influjo político que ejercieron sus actividades culturales en el entorno. Con frecuencia, el Instituto organizó conferencias, conmemoraciones, veladas literarias, etc., en coordinación con intelectuales que permanecían en Pedro Sánchez, o que se hacían llegar de otros puntos de la isla con tal fin, como el abogado Justo Tur Puget o el Inspector Luís Alaminos Peña, extendiéndolas luego a poblados cercanos como Hato Mayor, La Romana, San Pedro de Macorís y San Rafael del Yuna, adonde llevaron la poesía de Lorca, las letras del Siglo de Oro español, el teatro de Alejandro Casona y, sobre todo, el discurso por la movilización antifascista.

También llegaron al puerto de San Pedro de Macorís profesores de Pedro Sánchez. No los de la academia que dirigía Pingarrón, que radicaban allí desde que llegaron al país, pero si los que formaron la Academia Benefactor Trujillo con Miguel Arnedo Díaz, que la dirigió, y los maestros nacionales Lorenzo Berdala Pardo y Pedro Atienza Simarro, así como otros tantos que seguirían trayectorias aisladas laborando en escuelas dominicanas o enseñando en su propio domicilio, como Luis Espinal. ${ }^{40}$ De hecho, algunos profesores radicados en la Colonia realizarían traslados a localidades distantes, como Puerto Plata, donde formaron el Instituto Luis Vives con apoyo de un comerciante local apellidado Paieowonski. ${ }^{41}$

Las escuelas establecidas en La Romana —en la llanura azucarera del este- o las que se instalaron en Salcedo, Moca, San Francisco de Macorís y La Vega —en la región del Valle del Cibao-, no se deben a la diáspora desde las colonias.

Poco tenía que ver Tiburcio Millán López, el maestro nacional que fundó el 1. ${ }^{\circ}$ de febrero de 1940 el Instituto Escuela Cervantes en la ciu-

\footnotetext{
${ }^{40}$ Referido por Álvarez, que también cita como enseñantes en el puerto a los refugiados Pedro Aldabaldetrecu, José Augusto Pedrero Pérez, Vicente Riera Llorca y su esposa Carmen, Pedro Artero Amil y Antonio Muñoz Lizcano, casos que no hemos podido corroborar. Fermín Álvarez Santana, Héroes anónimos. Cien años de magisterio en San Pedro de Macorís (San Pedro de Macorís: Impresora León, 1997).

${ }^{41}$ Entrevista al señor Francisco Querol Amorós, Ciudad de México, 5 de septiembre de 1989, colección personal del autor. En principio Querol laboró en la «Academia Renovación», pero salió de ella por el poco salario que obtenía.
} 
dad de La Romana, ${ }^{42}$ con las células comunistas de Pedro Sánchez, pues era leal a la facción contraria en el espectro político del exilio. Posiblemente llegase de otra ciudad (como el contiguo puerto de San Pedro de Macorís, al que se derivaron contingentes arribados a Santo Domingo), pero el hecho es que allí implantó y sostuvo ese instituto durante tres años (al menos), con una oferta educacional que contemplaba la enseñanza primaria superior y las especialidades técnicas.

En la región cibaeña, el Colegio España creado por Gregorio Salanova Orueta en Salcedo, ${ }^{43}$ o el Instituto Escuela Hispano Americano gestado en Moca por Francisco Ruiz Avilés, posiblemente se debiesen a la diáspora de los llegados a la «Finca Generalísimo» aledaña a la ciudad de San Francisco de Macorís, desde donde sí salieron Antonia Blanco y Emilio Aparicio Martínez para fundar su Escuela de Declamación, embrión de tantos influjos posteriores en la vida teatral dominicana. ${ }^{44}$

En la ciudad de Santiago, José Rivero Orellana (maestro nacional, ex director de colonias escolares en la región de Málaga) instaló un Nuevo Instituto Escuela Cervantes, que nació en la coyuntura del cierre del colegio que sostenían en la ciudad los padres lasallistas. ${ }^{45} \mathrm{En} \mathrm{La}$ Vega, José Bárzana Bárzana (maestro nacional) implantó la Nueva Institución de Cultura, que impartía enseñanza primaria y secundaria, en la que laboraron Ramón Costa Jou, Jorge Ivón la Bardera, Emilio García Goicoechea, además de su esposa Clara Estrada de Bárzana y su hermano Eduardo Bárzana Bárzana — de la «afamada saga de maestros comunistas asturianos», como indica De Luis-. ${ }^{46}$

\footnotetext{
42 «Reportajes de La Opinión: La Romana, centro de progreso en tierras orientales», La Opinión (Ciudad Trujillo), 28 de agosto de 1944.

43 «Del Colegio España al Generalísimo Trujillo Molina», La Nación (Ciudad Trujillo), 9 de agosto de 1941.

${ }^{44}$ La presencia de los refugiados en la formación del mundo teatral dominicano merece un estudio detallado. No sólo por su conducción de proyectos institucionales - como el Teatro Universitario que dirigió Vicente Llorens o el Teatro Escuela de Arte Nacional, en el que varios colaboraron como profesores- sino por el impulso que imprimieron al ambiente teatral sus propios centros escolares y sociales, como el de Aparicio y Blanco que ahora se cita, o las escuelas de declamación que impulsaron Maruja Fernández en Santo Domingo (Sociedad de Arte Dramático) y Carola Yonmar en Santiago (Escuela de Arte Dramático).

45 «Nuevo Instituto Escuela», La Nación (Ciudad Trujillo), 23 de septiembre de 1940.

${ }^{46}$ De Luis Martín, «El exilio de la Federación», 214.
} 
En San Pedro de Macorís, el ingeniero Joaquín Hurtado Marhuenda estableció el Instituto de Estudios Técnicos en agosto de 1940, proyecto que parece haberse abocado esencialmente a la realización de ciclos de conferencias de ese carácter, presumiblemente con el fin de captar el interés del público por esos estudios, ya que no existe indicio de que contase con un plantel. Un año más tarde, varios de los participantes en las conferencias del instituto aparecen involucrados en las llamadas «Cátedras Populares de Educación» que impulsó el Ateneo local.

Finalmente, la ciudad de Santo Domingo fue el marco donde se desarrollaron los cuatro proyectos con que cerramos este recuento: la Escuela Española, la escuela del Centro Español Democrático, el Instituto Escuela, y la Escuela Superior de Ciencias Económicas.

La Escuela Española no dejó muchos rastros. Aparentemente surgió tras la disolución del Instituto Hostos de El Seibo, pues tres de sus enseñantes — Jesús Abadías, Claudio Fournier y Justo Tur- la tenían establecida allí hacia mediados de 1943, poco antes de abandonar el país. ${ }^{47}$ Tampoco sobre la que sostuvo el Centro Español Democrático puede saberse gran cosa, a pesar de que las actividades del Centro contaron con la difusión de dos publicaciones periódicas de los refugiados -Por la República y Juventud Española, ambas de tendencia comunista-. Fue la única que se planteó una agenda cultural interesada en transmitir contenidos españoles a los hijos de los refugiados, si bien sostuvo (como lo hizo el Club Hispano Dominicano de Pedro Sánchez) una sección de alfabetización para dominicanos adultos y otra de capacitación.

El Instituto Escuela de Guillermina Medrano Aranda (maestra graduada en la Normal de Valencia con estudios de ampliación pedagógica) fue uno de los proyectos más duraderos, pues se inauguró en enero del año 1941 y funcionó bajo su dirección hasta $1945 .{ }^{48}$ Como se dijo, es el único proyecto que ha podido reconstruirse históricamente, por lo que haremos sólo algún señalamiento más adelante.

La Escuela Superior de Ciencias Económicas constituye uno de los proyectos más interesantes de los enseñantes republicanos por el hito que representó en la historia de la enseñanza de la economía en el país. En origen, la escuela se llamó Escuela de Altos Estudios Mercantiles y

\footnotetext{
47 Joan Durán, «Catalans a la República Dominicana», La Nostra Revista 5 (1946): 185.

48 Medrano y Cruz, Experiencia de una maestra, 348-349.
} 
se estableció con ese nombre en los primeros días de 1940. En la solicitud de autorización que dirigieron al Secretario del ramo sus fundadores, José Sorribes Soler y Manuel Alepuz Zanón, argumentaban:

La Contabilidad, las Matemáticas Financieras, la Tecnología Industrial, la Economía Política estimulada siempre en su estudio por los problemas de producción y consumo, y tanto más las cuestiones de créditos, cambios contingentes, divisas, barreras arancelarias, etc., no pueden encerrarse en los elementales conocimientos de los empleados modestos, Tenedores de libros, Taquígrafos y Mecanógrafos, que hoy constituyen las enseñanzas de las Escuelas de Comercio en la República Dominicana. ${ }^{49}$

$\mathrm{Y}$, en efecto, el primer centro en el que se cursaron estudios de Auxiliar Mercantil, Contador Mercantil y Ciencias Económicas en el país fue aquella escuela, que luego daría lugar a la creación de la Escuela de Administración y Contabilidad, centro público sostenido por la Secretaría de Estado del Tesoro y Comercio, que dirigiría el propio Sorribes hasta que abandonó el país en 1945.

El impacto de las actividades de la escuela en términos de la historia de la enseñanza de la teoría económica en la República Dominicana es aún tarea pendiente. Su creación aparentemente influyó los estudios secundarios al motivar la reforma de las Ordenanzas 505’37 y 506’37 sobre enseñanza comercial ${ }^{50}$ y generar la creación de la Cátedra de Química y Tecnología Industrial en la Universidad de Santo Domingo. ${ }^{51}$ La escuela y sus profesores —entre los que encontramos a Domingo Martínez Barrio y a José Castañeda Cúndaro- sostuvieron la revista Finanzas, que también fue la primer publicación en su género en la historia del país.

\section{Los enseñantes en escuelas dominicanas}

Quizás unas treinta personas trabajaron en instituciones dominicanas, generalmente en centros de enseñanza superior como las escuelas secundarias, las Normales o los institutos de carácter técnico. En la enseñanza

\footnotetext{
49 «Editorial», Finanzas 1, no. 9 (1942): 5.

50 «Enseñanza», Finanzas 1, no. 1 (1941): 19-24.

51 «Editorial», Finanzas 2, no. 20 (1943): 5.
} 
primaria pública (y privada) su presencia es escasa, posiblemente por la fuerte competencia por ocupar esos cargos por parte de las crecientes camadas de egresados de las escuelas normales, con quienes el trujillismo sostenía la alianza corporativa que claramente selló la realización del Primer Congreso de Estudiantes Normalistas en noviembre de 1945.

No obstante, por preferencias vinculadas con aspectos raciales, algunos laboraron en escuelas particulares sostenidas por los ingenios azucareros para servicio de su personal administrativo, que era usualmente extranjero (norteamericano, cubano o puertorriqueño). José Farreras Borull, profesor en la escuela del Ingenio Consuelo hacia 1942, explica que varios enseñantes de Pedro Sánchez impartieron materias en ese tipo de escuelas, entre ellos uno de los dos hermanos Bárzana Bárzana, que fue a quien Borull sustituyó al llegar al ingenio; también Costa Jou refiere haber trabajado en una escuela de ingenio en el Central Romana. ${ }^{52}$

Sin embargo, por efecto de esa misma política de alianza - que, entre otras cosas, se expresó en la expansión de las instituciones de formación de maestros-, muchos lograron insertarse como enseñantes en las escuelas Normales sostenidas por el Estado, como puede verse en el cuadro 3.

En las Normales, los enseñantes españoles tendieron a impartir materias que respondían a su perfil, aspecto que no es posible entrar a detallar aquí. Aunque en éstas tendieron a emplearse los que hemos llamado Enseñantes Refugiados (algo lógico, pues se requerían certificaciones para impartir en ellas), también encontramos casos de refugiados que enseñan por tener un cierto perfil formativo general que les abrió paso en la enseñanza de los idiomas (particularmente francés, aunque también portugués, idioma que pasó a formar parte del currículum a raíz de un curioso acercamiento del dictador con el Brasil: Cluet, Mascaró y Funcia lo impartieron, por ejemplo) o las matemáticas, como fue el caso del ingeniero militar Manuel Calvo Cano. Recordando sus días en la ciudad de San Cristóbal, la maestra Pilar Munárriz de Leal señala: «A mí me dieron también unas clases de la Normal, entre ellas Agricultura tropical de la que no sabía más que lo que estudiaba la víspera de dar clase, pero me defendía». ${ }^{53}$

\footnotetext{
52 Entrevistas a José Farreras Borull y Ramón Costa Jou.

${ }_{53}$ Pilar Munárriz de Leal, Memorias anecdóticas de una exiliada "por la gracia de Franco», http://m. dugifonsespecials.udg.edu/handle/10256.2/14378 (consultado el 24-10-2017).
} 
Cuadro 3. Enseñantes españoles en Escuelas Normales

\begin{tabular}{|c|l|}
\hline Lugar & \multicolumn{1}{|c|}{ Profesores } \\
\hline \multirow{2}{*}{ Santo Domingo } & \multicolumn{1}{|c|}{} \\
\cline { 2 - 2 } & Federico Izquierdo, Manuel Cluet Santiveri \\
\cline { 2 - 3 } Santiago & Fernando Sainz Ruiz, Vicente Llorens Castillo \\
\hline Puerto Plata & Manuel Pumarega García \\
\hline San Pedro de Macorís & $\begin{array}{l}\text { Lorenzo Berdala Pardo, Ángel Pingarrón Hernández, José Mataix, } \\
\text { Encarnación Funcia Armenteros }\end{array}$ \\
\hline San Fo de Macorís & Ricardo Pons Rubio, Carlos González Sanz, Ulpiano Díaz Herrero \\
\hline San Cristóbal & Luis Leal Crespo, Pilar Munarriz de Leal \\
\hline Montecristy & Manuel Calvo Cano \\
\hline Barahona & Malaquías Gil Arantegui, Francisco Acacio Martínez \\
\hline Azua & Miguel Ángel Morales \\
\hline San Juan de la Maguana & José Bellosta Otín, Eduardo Fajardo Suárez \\
\hline
\end{tabular}

${ }^{a}$ Normal Superior Presidente Trujillo y Normal de Señoritas.

Fuente: elaboración propia con base en distintos reportes.

Otras instituciones de enseñanza superior en las que tuvieron cabida figuran en el cuadro 4.

No es posible comentar en este marco los distintos casos. Se trató de instituciones públicas, exceptuado el Instituto Comercial García y García. En algunas de ellas —como la Escuela de Administración y Contabilidad, el Teatro-Escuela de Arte Nacional y, en gran medida, el Conservatorio Nacional de Música y Declamación-, el papel de los exiliados fue seminal, derivando el interés del Estado por su creación y sostenimiento como centros de enseñanza pública en los antecedentes pobremente instalados por los llegados, que luego pasaron a dirigirlos. 
Cuadro 4. Instituciones de Enseñanza Superior

\begin{tabular}{|c|c|c|}
\hline Lugar & Institución & Profesores \\
\hline \multirow{9}{*}{ Santo Domingo } & Instituto Comercial García y García & Poncio Sabater Casellas \\
\hline & Escuela de Contadores Públicos & Ricardo Martín Serra \\
\hline & Escuela de Enfermería & Dolors Canals Farriols \\
\hline & Escuela Industrial de Señoritas & María Díaz del Solar \\
\hline & Escuela de Admón. y Contabilidad & José Sorribés Soler \\
\hline & $\begin{array}{l}\text { Conservatorio Nacional de Música } \\
\text { y Declamación }\end{array}$ & $\begin{array}{l}\text { Maruja Fernández } \\
\text { Félix Gordillo } \\
\text { Alfredo Matilla Jimeno }\end{array}$ \\
\hline & Teatro-Escuela de Arte Nacional & $\begin{array}{l}\text { Antonia Blanco } \\
\text { Emilio Aparicio Martínez }\end{array}$ \\
\hline & Escuela Diplomática y Consular & $\begin{array}{l}\text { Alfredo Matilla Jimeno } \\
\text { José Almoina Mateos } \\
\text { Segundo Serrano Poncela } \\
\text { Jesús Galíndez Suárez }\end{array}$ \\
\hline & $\begin{array}{l}\text { Escuela de Oficiales del Ejército } \\
\text { Dominicano }\end{array}$ & $\begin{array}{l}\text { Ángel Rayo del Campo } \\
\text { Manuel Calvo Cano } \\
\text { Aurelio Matilla Jimeno }\end{array}$ \\
\hline San Pedro de Macorís & Liceo Secundario José Joaquín Pérez & Miguel Anglada Romeu \\
\hline
\end{tabular}

Fuente: elaboración propia con base en distintos reportes.

\section{LA APROPIACIÓN DOMINICANA DE LA ESCUELA REPUBLICANA EN EL EXILIO}

Con las grandes limitaciones factuales que arrojan los escenarios que aquí hemos descrito, sólo de modo exploratorio podría hablarse de la existencia de un proceso general de apropiación sociocultural de la escuela y los enseñantes españoles por parte de la sociedad dominicana. Son tantos los aspectos de la vida de esas escuelas que se desconocen -enfoques y propósitos programáticos, prácticas cotidianas a que dieron lugar, testimonios de enseñantes y enseñados, por ejemplo- que resulta comprometedor el involucramiento del concepto de apropiación postulado por Chartier. ${ }^{54}$

\footnotetext{
${ }^{54}$ Roger Chartier, The cultural origins of the French Revolution (Durham: Duke University Press, 1991).
} 
Sin embargo, en la solución que pareció consensar hace algún tiempo la historiografía de la escuela rural posrevolucionaria mexicana, de entender la apropiación sociocultural de los proyectos escolares como el estudio de las condiciones que afectan a las formas y el sentido de la participación de los usuarios en la institución (como lo son la presencia de imaginarios y prácticas en relación con la cultura escolar, la acción estratégica de estructuras de poder insertas en el medio de implantación de la escuela, o la ausencia de condiciones materiales suficientes con las cuales implantar el propio dispositivo escolar), parece posible aislar y caracterizar ciertos condicionantes generales externos a las escuelas y a los enseñantes que definieron los procesos de apropiación local de sus proyectos escolares. ${ }^{55}$

La estrechez económica marcó el arranque de la práctica totalidad de los planteles y fue, sin duda, el gran factor condicionante del modo en que se insertaron en la vida dominicana. Aunque los embarques organizados por el Servicio de Evacuación de los Refugiados Españoles contaron con ciertos fondos para facilitar el establecimiento de los llegados, en lo formal estos se destinaron a los gastos de instalación en Colonias agrícolas. Esos recursos fueron gestionados por la Junta Pro-Inmigración Española, que parece no haber financiado ningún proyecto educativo hacia los días en que el inesperado incidente del trasatlántico Cuba puso en claro que la situación global del colectivo republicano sólo recomendaba la inmediata evacuación a otras repúblicas del continente, cosa que desestimuló la realización de inversiones y apoyos para proyectos de inserción en el país.

Esa debilidad material - palpable en el tipo de espacio escolar en que se materializaron los proyectos-, con su correlato de carencias para remunerar el esfuerzo de los enseñantes y la necesidad de ofrecer servicios educacionales en un mercado las más de las veces exiguo, crearon condiciones para que operasen formas de apropiación de los proyectos escolares de los republicanos adecuadas a la circunstancia dominicana: la necesidad de recurrir al patrocinio público y/o privado, cosa que abrió puertas a diversos tipos de influjo y uso social de la escuela.

\footnotetext{
55 Juan Alfonseca, «Para iniciar un debate. La apropiación social de los proyectos escolares», Memoria, Conocimiento y Utopía. Anuario de la Sociedad Mexicana de Historia de la Educación 1, no.1 (2005): 21-27.
} 
Varias formas de mecenazgo abrigaron estos proyectos escolares. Desde el del siempre ensalzado interés personal del «Benefactor» hasta el de actores privados en busca de intereses diversos, como el de la «Sociedad Renovación», o el del señor Paieowonski que citaba Francisco Querol, el hacendado "Mamón» Henríquez, ${ }^{56}$ la profesora Constanzo, ${ }^{57}$ y los variados séquitos del poder formal e informal del trujillismo.

En el mecenazgo de tipo oficial, la figura del dictador ocupó siempre un rol preeminente, que fue puesto de relieve en todos y cada uno de los actos de creación y conmemoración de los planteles. Como en el caso del Instituto Hostos, cuyo segundo aniversario brindó al diario $\mathrm{La} \mathrm{Na}$ ción, la oportunidad de dedicar un editorial planteando

La enseñanza particular [...] cuenta en esta era dominicana caracterizada por una amplia protección a todas las manifestaciones de la cultura [...] con el auxilio [...]del tesoro personal del Honorable Presidente de la República, el Generalísimo Trujillo [...] y de los fondos del Partido Dominicano que él dirige. ${ }^{58}$

Los actos de las escuelas de los refugiados no pudieron escapar al guion de legitimación pública del orden de dominación establecido, contando con la presencia invariante de figuras del poder como gobernadores provinciales, presidentes de Juntas Comunales del oficialista Partido Dominicano, Síndicos, inspectores escolares y miembros de la elite ciudadana local. De hecho, algunos proyectos contaron con el mecenazgo de esos agentes de las estructuras regionales del poder, como el mismo Instituto Hostos, que contó con el apoyo del general Ramírez, gobernador de la provincia y de figuras encumbradas del poder local como los hermanos Manuel y Carlos Goico, quienes exhibieron el establecimiento de los estudios normales en el instituto como una contribución personal al preclaro sentido patrio del Benefactor y Primer Maestro de la República, o de la Academia Renovación, en cuyos actos figuró ocasionalmente Pedro Pablo Villanueva, conspicuo personero del régi-

\footnotetext{
${ }^{56}$ Rico hacendado santiaguero que facilitó el local donde se instaló el «Nuevo Instituto Escuela Cervantes» de José Rivero Orellana, así como el local donde funcionaría el «Instituto Iberia» de Giménez Miralles.

${ }^{57}$ En El Seibo, Alcobé y sus compañeros trataron con la profesora Constanzo, quien parece haber cedido el espacio de su escuela para la instalación de los estudios secundarios.

58 «Editorial», La Nación (Ciudad Trujillo), 10 de septiembre de 1942.
} 
men y futuro gobernador, o del Instituto Escuela Cervantes, que bautizó su aula principal con el nombre de Francisco A. Gonzalvo en tributo del apoyo recibido de ese mecenas, a la sazón senador. ${ }^{59}$

Ese fue el discurso político que presidió el común de los actos, que regularmente se adornaban con el retrato del «Jefe», de los Padres de la Patria y, por supuesto, de aquellos a quienes contingentemente se dedicaba la ocasión. Era difícil que los llegados pudiesen eludir esas prácticas del ritual dictatorial. Nadie, en su sano juicio, se hubiese propuesto hacerlo, salvo que contase en su balanza con factores de poder como pareció ocurrir con el Instituto Escuela de Santo Domingo en la opinión de su directora. ${ }^{60}$

Las relaciones de dependencia con esos mecenazgos políticos condicionaron la apropiación local de los proyectos escolares de modo más profundo que el mero gesto de colocar al dictador en el nombre del centro, o de evocar los emblemas hispanistas por los que se inclinaba, o de hacer tributo de gratitud pública por la hospitalidad salvadora de un régimen que, por el contrario, perseguiría activamente la salida del colectivo. Así, esos mecenazgos parecieron conducir cierta negociación cultural respecto de principios pedagógicos claramente desterrados del ideario institucionista (que la prensa proclamaba arribado a tierras dominicanas), produciendo una forma dominicana de apropiación de los proyectos respecto de temas como la coeducación y la enseñanza religiosa. En la propaganda de la Academia Renovación podía leerse, por ejemplo: «enseñanza religiosa a solicitud de padres y tutores», «enseñanza mixta, con separación de sexos, bajo inspección y sugerencia de

\footnotetext{
${ }^{59}$ Sólo el nombre del dictador (o de sus familiares) podía colocarse como apelativo institucional, cosa que obscurece un poco la relación de los planteles españoles con sus respectivos mecenas. En la respuesta a la carta que le dirigieron los señores Ruíz y Jiménez solicitándole autorización para que la escuela que instalarían en Moca (ver cuadro 2) llevase su nombre, en agradecimiento al apoyo recibido, el rector Julio Ortega Frier lo rechazó señalando: «existe la ley número [...] 522 del 6 de junio de 1938 que, aunque no prohíbe de manera expresa que se designe los establecimientos docentes con nombres de personas vivas, del espíritu mismo de dicha [ley] se deduce [...] la citada prohibición». Julio Ortega Frier, «Carta», enero de 1940, Papeles de Julio Ortega Frier, BNRD.

${ }^{60}$ Según Guillermina Medrano, «nunca presidió nuestro centro el retrato del dictador, cosa peligrosa en un país donde por todas partes se leía, en grandes titulares, "Dios y Trujillo". El hecho de que entre nuestro alumnado figuraba la hija del Embajador norteamericano, así como los hijos de embajadores de Colombia, Perú, Venezuela, México y de miembros de varias delegaciones y consulados, nos ayudó, sin duda, a conservar nuestra independencia». Medrano y Cruz, Experiencia de una maestra, 348.
} 
las autoridades pedagógicas oficiales», asuntos sobre los que trazaba una política similar el Cristóbal Colón, en tanto del Nuevo Instituto Escuela Cervantes se afirmaba que «viene a sustituir al Colegio de la Salle, recientemente clausurado y continuará la labor de este plantel en el aspecto religioso». ${ }^{61}$

\section{ENSEÑANZA PRIMARIA ELEMENTAL Y SUPERIOR.}

SEIS HORAS DIARIAS

Clases de 8 a $11 \frac{1}{2}$ a. m. y de 2 a 41 p. m.

Aplicándose los métodos modernos de enseñanza individualizada para el progreso autorítmico.

Procedimiento de globalización y lectura ideovisual. Plan de enseñanza de acuerde con los programas oficiales.

Enseñanza religiosa a solicitud de los padres o tutores.

\section{REPASOS DE PRIMERA ENSEÑANZA} POR TANDAS

Por la mañana de 8 a $11 \frac{1}{2}$ o por la tarde de 2 a 5 .

ENSENANZA SECUNDARIA Y NORMALISTA

Repasos por materias y cursos completos.

De $4 \frac{1}{2}$ a 7 p. m.

ENSEÑANZAS UNIVERSITARIAS

Repaso por materias.

ENSEÑANZA COMERCIAL

Preparación para:

CONTABLE Y TENEDOR DE LIBROS - ORTOGRA. HA - LENGUAJE - REDACCION - CALIGRAFA

Y RETORMA DE LETRRA - CLASES ESPECIALES DE IDIOMAS: INGLES Y FRANCES.

\section{Clases nocturnas GRATUITAS DE ALFABETIZACION \\ para adultos, de 7 a 8 p. $\mathrm{m}$.}

Imagen 1.

La oferta educacional de la «Academia Renovación»

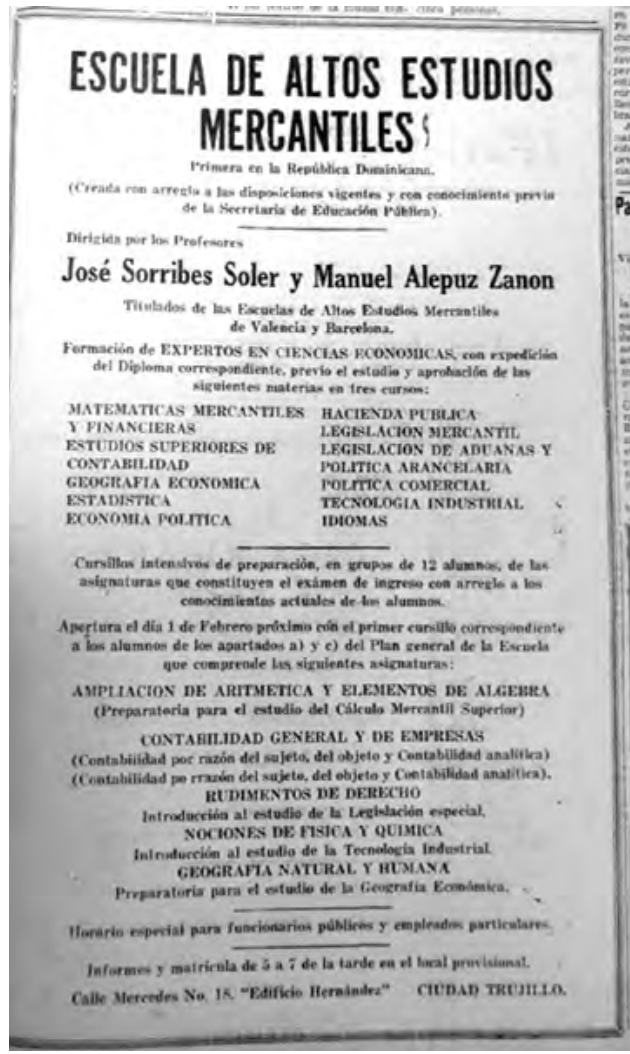

Imagen 2.

La oferta educacional

del «Instituto de Altos Estudios Mercantiles»

La debilidad financiera y las limitaciones del mercado educacional dominicano incidieron no sólo en el modo que señalamos, sino también en el propio perfil institucional de los servicios educacionales que ofre-

\footnotetext{
61 «Nuevo Instituto Escuela», La Nación (Ciudad Trujillo), 23 de septiembre de 1940.
} 
cieron. Se trató de proyectos típicamente polivalentes, abocados a varios niveles y tipos de formación, donde se combinaban —en un mismo espacio- los programas y grados oficiales de enseñanza con los estudios de tipo técnico, de formación para el trabajo y las especializaciones. La viñeta propagandística de la Academia Renovación que se reproduce a continuación deja ver el carácter multimodal de la enseñanza que imperó en la mayoría de los planteles creados por los exilados.

Esos rasgos multimodales - algo digno de contrastarse vis a vis con los planteles dominicanos, que más bien se especializaban por niveleran posibles por la existencia de una masa de enseñantes en condición de disposición social suficiente como para flexibilizar su actividad empleándose en varios centros, allí donde esto fue posible. ${ }^{62}$ Lo eran también - visto ahora desde las determinaciones que marcaba el contexto cultural-, porque las escuelas de los llegados enseñaban bien y sus alumnos obtenían una formación que los habilitaba para valerse de ella en, por ejemplo, el ingreso a las escuelas Normales, a la Universidad o para simplemente acreditar los exámenes oficiales del nivel de enseñanza primaria. Con mucha frecuencia, las notas alusivas a esos planteles expresan los altos porcentajes de acreditación obtenidos en los exámenes oficiales por su alumnado, constituyéndose este aspecto en dato regular de sus actos propagandísticos. En el reportaje citado sobre la Academia Antillana puede leerse:

Los resultados obtenidos hablan elocuentemente [...] viéndolo reflejado en los primeros exámenes que los alumnos efectuaban, arrojando el 100 por ciento de aprobados en todos los cursos. Para presenciar los exámenes de promoción se abrieron las puertas de par en par a fin de dar más publicidad a la excelente preparación de los educandos. ${ }^{63}$

Planteles con un discipulado de un amplio rango de edades y un gran número de rostros docentes fueron el tenor de los proyectos, que

\footnotetext{
${ }^{62}$ Algunos enseñantes laboraron simultáneamente en más de una de las escuelas españolas. En las ciudades mayores esto era posible porque existían, por ejemplo, escuelas Normales donde tomar algunas horas, En los sencillos poblados esto no era tan fácil y menos lo era en las Colonias. Incluso hubo varios que enseñaron cotidianamente en más de una ciudad de la banda este de la república.

${ }^{63}$ «Una escuela que honra la instrucción. La Academia Antillana».
} 
también — de modo, podría decirse, inherente- animaron atmósferas culturales estrechamente conectadas con sus actividades. Las aplaudidas Conferencias Sabatinas del Cristóbal Colón, las del Instituto de Estudios Técnicos, o las del Instituto Hostos y el Club Hispano-dominicano, antes comentadas, no fueron las únicas; también otros planteles las desarrollaron, vinculándolas con Ateneos y sociedades culturales dominicanas de modo que llegó a ser familiar en la vida dominicana de entonces.

La labor de extensión cultural que se desarrollaba en conexión con las escuelas tuvo un carácter plural, sólo parcialmente dedicado a la reflexión del problema político peninsular, aspecto que dio cierta peculiaridad a la proyección cultural de este segmento del exilio. En lo general, el tema republicano fue evitado por el régimen en reuniones públicas, dadas las relaciones formales (e informales, secretas y colaboracionistas) que sostenía con la España franquista. ${ }^{64} \mathrm{Al}$ entrar los Estados Unidos en la Segunda Guerra Mundial, toleró la discursividad anti-totalitarista de los refugiados «como demostración de vocación democrática y pro-occidental», como bien dice Cassá, pero lo cierto es que las atmósferas culturales que gestaron los planteles tendieron más a la divulgación del pasado cultural hispano, y a las expresiones regionales de la cultura española y sus implantes en América, que a temas de la propia coyuntura política española. Como un producto de la apropiación política que se produjo en la situación dominicana, esos actos muchas veces fortalecieron un imaginario remitido a la Conquista, promoviendo la formación de un discurso sobre la presunta comunidad dominico-hispana, y nutriendo y reproduciendo la tradición inventada sobre la que se erigía el imaginario trujillista.

Y, así como el profesor David Arias (enseñante refugiado en aulas de la Academia Renovación) disertaba sobre «Un cacique de Marién: reivindicación de algunas personalidades de los tiempos de la Conquista», así disertaron interlocutores dominicanos como Manuel A. Goico que,

\footnotetext{
${ }^{64}$ Además del artículo ya citado de Roberto Cassa puede consultarse: Matilde Eiroa y María Dolores Ferrero, «Rafael L. Trujillo y Francisco Franco: de los vínculos históricos a los compromisos coyunturales», IBEROAMERICANA 16, no. 61 (2016): 149-170.
} 
en el acto de inauguración del Instituto Hostos, habló sobre «la misión cultural de España en América en la época de la Conquista». ${ }^{65}$

Esa campaña en pos del hispanismo que alentaban las construcciones culturales del régimen fue clara y estratégicamente captada por Juan Pablo García, el director del Cristóbal Colón, que en la página liminar del folleto de presentación del instituto, colocó las siguientes palabras:

Deseamos contribuir a la labor iniciada con tanto acierto por las Autoridades Docentes, de reincorporar Santo Domingo a su tradición cultural más propia y por consiguiente la que ofrece perspectivas de una más auténtica fructificación: la cultura española; que siendo en su significado más hondo, universal, no excluye sino que presupone la asimilación de las mejores aportaciones espirituales de cualquier origen. ${ }^{66}$

Pero también hubo una apropiación racista en la mirada con que muchos dominicanos captaron la llegada y las acciones de los refugiados republicanos en suelo dominicano; mirada que era informada por la discursiva histórica sobre la panacea de las inmigraciones blancas y las políticas de contención racial de la negritud invasora que acechaba en suelo haitiano y la que procedía de las pequeñas posesiones inglesas en el Mar de las Antillas. No en vano, las Colonia Libertador, Juan de Herrera y El Llano se implantaron en la zona fronteriza con Haití, en tanto el asentamiento de refugiados en Pedro Sánchez y Villa Trujillo podían leerse como trincheras en el combate imaginario con la negritud anglófona y francófona que avanzaba por las llanuras azucareras del este del país.

\footnotetext{
${ }_{65}$ «Inaugurado el Instituto Hostos de enseñanza secundaria dirigido por un grupo de profesores españoles».

Este rasgo de la apropiación dominicana de los proyectos culturales de los exilados merece un análisis en profundidad, pues se produjo también en la pintura (basta ver la obra de Vela Zanneti o Rivero Gil, con escenas de la Conquista, obra expresamente encargada por el funcionariado trujillista en pos de esa comunidad imaginada) y la literatura (Galíndez, por ejemplo, fue premiado por sus "Cinco Leyendas del Trópico», formada por narraciones alusivas a ese tiempo histórico). Jesús de Galíndez, Cinco Leyendas del Trópico (Santo Domingo: Taller, 1984).
}

${ }^{66}$ Instituto Cristóbal Colón, 3. 
La idea de que la política de inmigración tenía sentidos en torno al mestizaje y la contención cultural fue algo común en la visión del pueblo dominicano, existiendo un gran número de testimonios de exiliados en el país que recuerdan que ésta modeló algunas de sus interacciones. ${ }^{67}$ Resulta muy interesante, en este sentido, el reportaje que La Nación dedicó a la Colonia Pedro Sánchez, mostrándola como una suerte de baluarte de carácter demográfico y racial:

La piel es la antesala del espíritu —argumenta La Nación-. En el Este hay un espíritu amorfo que hay que moldear. Encrucijadas de isleños. De Haití también. Hay un pretexto que se llama caña, que paga salario bajo, no vital y tiñe el paisaje con la borra de Turks Islands. No hay matices auténticos. Urge modelar un espíritu nativo. Y gran acierto fue llevar españoles al Este. Ojalá se llevaran más. Porque el Este es una avanzada de las Antillas menores: el negro de Turks Islands, el de Antigua, el de Barbados, el de Guadalupe, chocolates diversos, chocolates crueles. El paisaje necesita una ubre de blancura para ir enjuagando obscuridades.

El tema de la soberanía racial — «el Este es una avanzada de las Antillas menores», "la piel es la antesala del espíritu»- y el del mestizaje deseado con las inmigraciones blancas — «ir enjuagando obscuridades»—, cobra la clara expresión del complejo racial en la descripción de la escuela instalada por los colonos:

En la escuela hay niños de todas clases: blancos, trigueños, mulatos, negros. Los blancos son casi todos españoles. De los trigueños para abajo, nuestros. Pero ya vendrán los días, los meses, las lunas. Y junto a la espiga hinchada reventará otro muchachito blanco, trigueño, mulato. El blanco será hermanito de los otros blancos que vinieron nacidos. El mulato... ¡Ah!, ya el mulato es otra cosa. ${ }^{68}$

\footnotetext{
${ }^{67}$ Fidel Miró, el líder anarquista que luego marchó a México, recordaba que el administrador de la Colonia de «El Llano», al verlos trabajar la tierra les había exclamado, enfático: «¡Españoles! Ustedes no están impuestos a eso [en referencia al trabajo agrícola]; ustedes vinieron a encastar [esto es, a mejorar la raza]».

68 «Refugiados españoles en Pedro Sánchez», La Nación (Ciudad Trujillo), 6 de abril de 1940.
} 
Otras formas de apropiación racista de la inmigración española no la situaron en el combate con la negritud que amenazaba a la blancura imaginaria del pueblo dominicano, sino que la insertaron en relaciones de discriminación entre los propios dominicanos o entre éstos y los grupos extranjeros residentes en el país. Aquellos tutores en domicilios de la élite burocrática local, lo mismo que los que lo fueron en hogares de la vieja colonia española, como vimos, dieron testimonio sobre el valor y el papel que jugaron en tanto sustituían el trato con sus pares dominicanos.

También se asoció el uso de los nuevos enseñantes blancos como mecanismo de distinción entre clases sociales. Era distinción lo que, sin duda, ofrecía el Cristóbal Colón, con su énfasis en la "corrección», las buenas maneras, sus uniformes de gala y sus prácticas culturales, como la hora del «thé» — costumbre inusual entre los dominicanosque se servía a externos e internos en la «espaciosa finca situada, como conviene a esta clase de instalaciones, a una distancia prudencial de la ciudad, de manera que los alumnos alejados lo suficiente de la insalubridad del casco urbano, tengan [...] fácil y rápida comunicación». ${ }^{69}$ También lo era el pasar a formar parte del alumnado del Instituto Escuela de la ciudad de Santo Domingo, plantel preferido por el cuerpo diplomático extranjero acreditado en la ciudad capital.

Por supuesto, las formas de apropiación descritas sólo revelan escenarios de uso social de la escuela republicana en el exilio coherentes con el modelo de dominación vigente en la sociedad dominicana de entonces. Hubo, desde luego, formas que no tuvieron ese carácter sistémico; formas que muchos dominicanos recuerdan por su valor contestatario del orden dictatorial, cuyo análisis es tarea pendiente. La flexibilización del código racial que practicaron los refugiados en sus escuelas fue un difuso hecho cultural cuyo impacto en la sociedad dominicana es difícil aquilatar. También la flexibilización del trato entre maestros y alumnos que recuerda Mercedes Sabater, ${ }^{70}$ o el posicionamiento frente a la guerra mundial y al fascismo que interpelaba las simpatías que despertaba entre los dominicanos el avance

\footnotetext{
${ }^{69}$ Instituto Cristóbal Colón, 16.

70 Entrevista a Mercedes Sabater.
} 
alemán, ${ }^{71}$ o la elusión de colgar en sus espacios la imagen del «Benefactor», que destaca Medrano, constituyeron algunos rasgos contestatarios de la apropiación cultural que los dominicanos hicieron de sus escuelas.

\section{Nota sobre el autor}

Juan B. Alfonseca Giner de los Ríos es Doctor en Estudios Latinoamericanos por la Universidad Nacional Autónoma de México. Ha desarrollado investigación histórica en materia de economía de la producción agraria, migración internacional y procesos de escolarización. Labora como docente e investigador en el Instituto Superior de Ciencias de la Educación del Estado de México. Actualmente desarrolla en esta institución un estudio sobre la expansión de la escuela popular pública en contextos rurales de México y la República Dominicana. Miembro fundador de la Sociedad Mexicana de Historia de la Educación (SOMEHIDE). Forma parte del Sistema Nacional de Investigadores.

\section{REFERENCIAS}

Alfonseca Giner de los Ríos, Juan. «Para iniciar un debate. La apropiación social de los proyectos escolares». Memoria, Conocimiento y Utopía. Anuario de la Sociedad Mexicana de Historia de la Educación 1 (2005): 21-27.

Alfonseca Giner de los Ríos, Juan. El incidente del trasatlántico Cuba. Una historia del exilio republicano español en la sociedad dominicana, 1938-1944. Santo Domingo: Archivo General de la Nación, 2012.

Álvarez Santana, Fermín. Héroes anónimos. Cien años de magisterio en San Pedro de Macorís. San Pedro de Macorís: Impresora León, 1997.

Amat y Castells, Vanessa. «Passat i present de la impremta escolar i els llibres de vida: les tècniques Freinet a l'Estat espanyol a propòsit d'algunes publicacions recents». Educació i Història: Revista d'Història de l'Educació 23 (2014): 207-225.

Cassá, Roberto. «Incidencia política de los republicanos españoles en la República Dominicana». En El exilio español en la sociedad dominicana, coord.

\footnotetext{
${ }^{71}$ Un editorial del El Génesis, semanario que dirigía la profesora dominicana Eloina Constanzo en El Seibo, muestra el impacto de la prédica antifascista de sus amigos del «Instituto Hostos». «¡Equivocadosj», El Génesis (El Seibo), 13 de septiembre de 1941.
} 
por Reina Rosario Fernández, 113-130. Santo Domingo: Archivo General de la Nación, 2010.

Cruz, José Ignacio. La educación republicana en América, (1939-1982). Valencia: Generalitat Valenciana, 1994.

De Luis Martín, Francisco. «El exilio de la Federación Española de Trabajadores de la Enseñanza en México (1939-1949)». Tzintzun. Revista de Estudios Históricos 63 (2016): 207-241.

Del Castillo, José y Manuel García Arévalo. «La emigración republicana española: aportes a la República Dominicana». En El exilio republicano español en la sociedad dominicana, coord. por Reina Rosario Fernández, 235-268. Santo Domingo: Archivo General de la Nación, 2010.

Durán, Joan. "Catalans a la República Dominicana». La Nostra Revista 5 (1946): 19.

Eiroa, Matilde y María Dolores Ferrero. «Rafael L. Trujillo y Francisco Franco: de los vínculos históricos a los compromisos coyunturales». IBEROAMERICANA 16, no. 61 (2016): 149-170.

Galindez, Jesús de. Cinco leyendas del trópico. Santo Domingo: Taller, 1984.

González Tejera, Natalia. «Nómina de republicanos españoles refugiados en República Dominicana (1940-1941)». Boletín del Archivo General de la Nación 135 (2013): 33-154.

Jarne, Antonieta. "Geografías familiares bajo la dictadura franquista: exilio, clandestinidad, prisión». Hispania Nova. Revista de Historia Contemporánea 8 (2008)

Llorens, Vicente. Memorias de una emigración. Barcelona: Ariel, 1975.

Lozano Seijas, Claudio (ed.). 1939, el exilio pedagógico. Estudios sobre el exilio pedagógico republicano español de 1939. Barcelona: Cooperativa Universitaria Sant Jordi, 1999.

Marqués Sureda, Salomó y José Martín Frechilla. La labor educativa de los exiliados españoles en Venezuela. Caracas: Universidad Central de Venezuela, 2002.

Màrques Sureda, Salomó. «Sobre l'exili del magisteri republicà (1936-39). Reflexions i suggeriments». Educació i Història: Revista d'Història de l'Educació 12 (2008): 41-64.

Martínez Gorroño, María. «La educación en la Colombia liberal de los años 30 y 40: la trascendente contribución del exilio español consecuencia de la guerra civil de 1936-1939». Migraciones \& Exilios 4 (2003): 9-30.

Medrano de Supervía, Guillermina. «Mi exilio en la República Dominicana: una obra educativa y varias mujeres ejemplares». En Cincuenta años de exilio español en Puerto Rico y el Caribe 1939-1989, 345-355. A Coruña: Edicios Do Castro, 1991. 
Medrano, Guillermina y José Ignacio Cruz. Experiencia de una maestra republicana. Valencia: Publicaciones de la Real Sociedad Económica de Amigos del País, 1998.

Molina, María. «Republicanos españoles en el Caribe y en México. Tres naciones, tres momentos, un mismo exilio». En 1939, el exilio pedagógico, editado por Claudio Lozano, 119-133. Barcelona: Cooperativa Universitaria Sant Jordi, 1999.

Munárriz de Leal, Pilar. Memorias anecdóticas de una exiliada "por la gracia de Franco». http://m.dugifonsespecials.udg.edu/handle/10256.2/14378

Orgaz, Mercedes. Testimonio desde la retaguardia. Las memorias de una funcionaria del Gobierno de la República durante la Guerra Civil y el exilio. Barcelona: Fundació Privada Ciencia en Societat, 2007.

Reyes, Juan José. "Escuelas, maestros y pedagogos». En El exilio español en México, 1939-1982, 177-205. México: Ediciones Salvat-Fondo de Cultura Económica, 1982.

Ruíz del Árbol Cana, Antares. Hacer España en América, Guillermina Medrano Aranda (1912-2005): la pervivencia del Magisterio Republicano en el exilio americano. Santo Domingo: Academia Dominicana de la Historia, 2015. 


\section{ANEXOS}

\begin{tabular}{|c|c|c|}
\hline \multicolumn{3}{|c|}{ Listado de Enseñantes Refugiados en la República Dominicana, 1939-1945 a } \\
\hline Abadía Lamuela, Jesús & Estrada de Barzana, Clara & Muñoz Lizcano, Julián \\
\hline Alaminos Peña, Luis & Farreras Borrull, José & Nozal Alonso, Luis \\
\hline Alcobé Biosca, José & Fernandez de Pozo, Carmen & Ocaña Guarino, Manuel \\
\hline Aldaz Elso, Cecilio & Fernández de Saiz, Rosa & $\begin{array}{l}\text { Ocaña Sánchez de Ocaña, } \\
\text { Fraterna }\end{array}$ \\
\hline Aldaz Elso, Juan & Fernández de Serván, Antonia & Ocaña Sánchez, Francisco \\
\hline Aller Alberdi, Sofía & Fernández Posada, Fermín & Paez Fernandez, Manuel \\
\hline Almoina Mateos, José & Ferrer Stengre, Joaquín & Palacín Iglesias, Gregorio B. \\
\hline Alonso Jacoby, Elvira & Figueroa Castellanos, Aurelio & Pedreira Rumbo, Manuel \\
\hline Alonzo Fernández, Vicente & Folch Pi, María & Perales Frigols, Pablo \\
\hline $\begin{array}{l}\text { Álvarez-Santullano Tejerino, } \\
\text { Gloria }\end{array}$ & Gandariasbeitia, Gaiska & Pérez González, José Manuel \\
\hline Alvero, Francisco & Garcia de Mascaro, Carmen & Pérez Real, Luís \\
\hline Antuna Suarez, David & García García, Julio & Pijoan Querol, Avelina \\
\hline Argomaniz Martínez, Ricardo & García Goicochea, Emilio & Pingarrón Hernández, Ángel \\
\hline Arnedo Díaz, Miguel & García Gómez, Purificación & Pons Rubio, Ricardo \\
\hline Artero Bernard, Felix & García Jarabo, Amparo & Puyuelo Callén, María \\
\hline Atienza Simarro, Pedro & García Jarabo, Josefa & Querol Amorós, Francisco \\
\hline Bárzana Bárzana, Eduardo & García Meseguer, Antonio & Rivero Gil de Durán, María \\
\hline Bárzana Bárzana, José & García Rodríguez, Carmen & Rivero Gil, Valentina \\
\hline Bellosta Otín, José & García Santesmases, Miguel & Rivero Orellana, José \\
\hline Bellosta, Marcelino & García, Serafín & Robles Díaz, Eduardo \\
\hline Benavente De Blasco, Emilia & Gilabert Barceló, José & Rolland Goitia, María Cristina \\
\hline Benavides Shelly, Miguel & Gómez de Rodriguez, Mercedes & Roure Canosa, Josefa \\
\hline Benjumea Suárez, Mateo & González Jerez, José María & Rovira, Joaquín \\
\hline Berdala Pardo, Lorenzo & González Nieto, Antonio & Rueda de Iranzo, Raquel \\
\hline Blanco Martínez-Tejerino, María & Goñi Argarate, Luís & Sabater Casillas, Poncio \\
\hline Blasco Sanpedro, Fernando & Huber de Ojinaga, Marta & Sainz Ruiz, Fernando \\
\hline
\end{tabular}


Juan B. Alfonseca Giner de los Ríos

Listado de Enseñantes Refugiados en la República Dominicana, 1939-1945

\begin{tabular}{|c|c|c|}
\hline Burell y Mata de González, María & Hurtado Marhuenda, Joaquín & Salanova Orueta, Gregorio \\
\hline Burgos Ramos, Frutos & Hurtado Polo, Antonio & Salas Fernández, Antonio \\
\hline Calvo Cano, Manuel & Jimenez Sanchez, Jose & Sales Valles, Joan \\
\hline Campa Claverol, Juan & Lafarga de San Cristóbal, Carmen & Sánchez de León y Maeso, Tomás \\
\hline Campos Campos, Severino & Leal Crespo, Luis & Sánchez Pérez, Enrique \\
\hline Campuzano García, Miguel & Llor Magre de Andrés, María D. & Sanz García de Barrio, Carmen \\
\hline Cano Crespo, Antonio & Llorens Castillo, Vicente & $\begin{array}{l}\text { Sarmiento de la Barrera-Caro, } \\
\text { Carmen }\end{array}$ \\
\hline Carbo Carbo, Eusebio & López de Sardí, Juan Antonio & Segoviano Nuñez, Eugenio \\
\hline Cartea Juan, Alvaro & López Gimeno, José & Segura Colbe, Julio \\
\hline Chacón Rey, María Auxiliadora & Marchan de Perez, María & Sendra Siscart, Juan \\
\hline Cluet Santiveri, Manuel & $\begin{array}{l}\text { Martín de Jorge Arellano, } \\
\text { Gregorio }\end{array}$ & Solana Ferrer, Alejandro \\
\hline Cortichs de Mora, Estrella & Martinez de Bujando, María & Suárez Valles, Manuel \\
\hline Costa Jou, Ramón & Martínez Surroca, Antonio & $\begin{array}{l}\text { Ugarte de Palacin, Ángeles de la } \\
\text { Vega }\end{array}$ \\
\hline Cruz Moreno, María & Masdefiol Bertran, Jose & Uriarte Prieto, Aurora \\
\hline Dalmau Arroyo, Armonía & Mataix Antonlin, José & Urrestarazu Falces, Sinesio \\
\hline De Haro Iribarne, Gines & Matilla Jimeno, Alfredo & Valles Cuesta, Pilar \\
\hline De los Ríos de Beléndez, Dolores & Menéndez Catrain, María & $\begin{array}{l}\text { Vera Fernández de Córdova, } \\
\text { Francisco }\end{array}$ \\
\hline De Urreiztieta Errekalde, Iñaki & Merida de Rivero, Carmen & Xena Torrent, José \\
\hline Diaz Alejo y Diaz, Daniel & Mestres Armora, Arturo & \\
\hline Díaz Álvarez, José & Millán López, Tiburcio & \\
\hline Díaz Cardama de Trujillo, Marina & Mingarro y San Martín, José & \\
\hline Díaz Herrero, Ulpiano & Monico Castelló, Antonio & \\
\hline Escobar Vallejo, Ismael & Montañola Casul, Cosme & \\
\hline Estornas, José & Munarriz de Leal, Pilar & \\
\hline
\end{tabular}

${ }^{a}$ Lista de las personas que declararon a la autoridad dominicana la profesión de enseñante al arribar al país. Las celdas con color marcan a los que desempeñaron esa actividad en la República Dominicana.

Fuente: Censo General de Refugiados Republicanos 1938-1945 (en construcción). 


\begin{tabular}{|l|}
\hline Listado de Refugiados Enseñantes en la República Dominicana, 1939-1945 \\
\hline Acacio Martínez, Francisco \\
\hline Adabaldetrecu, Pedro \\
\hline Anglada Romeu, Miguel \\
\hline Aparicio Martínez, Emilio \\
\hline Artero Amil, Pedro \\
\hline Barberán Manuel \\
\hline Bargallo Cervello, Pedro \\
\hline Blanco, Antonia \\
\hline Canals Farriols, Dolores \\
\hline Díaz de Solar, María L. \\
\hline Espinal, Luis \\
\hline Fajardo Suárez, Eduardo \\
\hline Fernández de Farber, Maruja \\
\hline Forné Farreres, José \\
\hline Fournier, Claudio \\
\hline Funcia Armenteros, Encarnación \\
\hline Gallego, Felipe \\
\hline Gil Arántegui, Malaquías \\
\hline González Sanz, Carlos \\
\hline Gordillo, Félix \\
\hline Medrano, Guillermina \\
\hline Ivón La Barbera, Jorge \\
\hline Izquierdo, Federico \\
\hline Jiménez Millares, José \\
\hline Jose Abella Peset \\
\hline León Garre, Aniceto \\
\hline Mascaró Navas, Juan \\
\hline Miró Solanes, Fidel \\
\hline Morales, Miguel Ángel \\
\hline Muñoz Lizcano, Antonio \\
\hline Pedrero Pérez, José Augusto \\
\hline Pumarega García, Manuel \\
\hline Recio de Millares, Luisa \\
\hline Rial, José \\
\hline Riera Llorca, Vicente \\
\hline Ruiz Avilés, Francisco \\
\hline Sorribes Soler, Jesús \\
\hline Ulibarri, Cristina \\
\hline Viñuales, Mariano \\
\hline Yonmar, Carola \\
\hline
\end{tabular}

a Se trata de personas que no habiendo declarado profesión de enseñante al arribar al país, se desempeñaron en ella. 